\title{
Conflicts with Multiple Battlefields
}

\author{
Dan Kovenock \\ Brian Roberson
}

\author{
CESIFO WORKING PAPER NO. 3165 \\ CATEGORY 12: EMPIRICAL AND THEORETICAL METHODS \\ SEPTEMBER 2010
}
An electronic version of the paper may be downloaded
- from the SSRN website:
www.SSRN.com
- from the RePEc website:
- from the CESifo website:
www.RePEc.org
www.CESifo-group.org/wp




\title{
Conflicts with Multiple Battlefields
}

\begin{abstract}
This paper examines conflicts in which performance is measured by the players' success or failure in multiple component conflicts, commonly termed "battlefields". In multi-battlefield conflicts, behavioral linkages across battlefields depend both on the technologies of conflict within each battlefield and the nature of economies or diseconomies in how battlefield outcomes and costs aggregate in determining payoffs in the overall conflict.
\end{abstract}

JEL-Code: C72, D74, H56.

Keywords: conflict, contest, battlefield, Colonel Blotto Game, auction, lottery.

\author{
Dan Kovenock \\ University of Iowa \\ Department of Economics \\ Tippie College of Business \\ W284 PBB \\ 21 E. Market Street \\ USA - Iowa City, IA 52242 \\ dan-kovenock@uiowa.edu
}

\author{
Brian Roberson \\ Purdue University \\ Department of Economics \\ Krannert School of Management \\ 403 W. State Street \\ USA - West Lafayette, IN 47907 \\ brobers@purdue.edu
}

\section{August 2010}

[prepared for inclusion in the Oxford Handbook of the Economics of Peace and Conflict edited by Michelle R. Garfinkel and Stergios Skaperdas].

We have benefited from helpful discussions with Michelle Garfinkel, Mattias Polborn, Stergios Skaperdas, Balázs Szentes, and Alan Washburn. 


\section{Introduction}

Within the economic, information, military, and political sciences the study of conflict often examines environments in which the outcome of a given conflict is determined by performance in multiple component conflicts or "battlefields." In most studies linkages exist between the component conflicts that require study as an overall system. In this survey we examine conflicts comprised of component conflicts that are winner-take-all contests. That is, one of the two parties in the component conflict (players) wins the component conflict and the other loses. Examples of such conflicts include: (i) product innovation, which often involves procuring a collection of interrelated patents, (ii) counterterrorism efforts and information systems security, which involve the defense of complex networks of different targets, each of which may be viewed as a battlefield, and (iii) presidential campaigns, which involve competing to win a majority of the votes within each state in a combination of states that results in an Electoral College victory. In each of these examples behavior and payoffs across the complete set of contests depend on the structural linkages between the individual contests. These linkages arise from economies or diseconomies in how battlefield outcomes and costs aggregate in determining performance in the overall conflict and may depend on the technology of conflict within each battlefield.

Structural linkages may be symmetric across players, as in presidential campaigns or product innovation, where the players share the same objective of securing any one of the winning combinations of contests - either a combination of states that wins the Electoral College or a combination of patents that result in the innovation. Conversely, structural linkages may be asymmetric across players, such as the weakest-link and best-shot objectives arising in the defense against terrorism, in which the loss of any single target may be sufficient to create a spectacular terrorism event but the entire collection of targets must be defended in order to prevent such an event.

Conflicts involving multiple component contests with structural linkages play a prominent role in the history of game theory. In one of the first problems examined in modern game theory, Borel (1921) introduced a foundational model of multiple contests with linkages. Borel's formulation, known as the Colonel Blotto game, is a constant-sum game involving two players who must each allocate a fixed amount of a resource over a finite number of contests.

Each player must distribute their resource without knowing their opponent's distribution of the resource. In each contest, the player who allocates the higher level of the resource wins, and the payoff for the whole game is a function of the sum of the wins across the individual contests. This particular game, which highlights the role of budget constraints as a structural 
linkage, was a focal point in the early game theory literature and captured the attention of prominent scholars across a range of disciplines (see, for example, Bellman 1969; Blackett 1954, 1958; Gross and Wagner 1950; Shubik and Weber 1981; Tukey 1949). The Colonel Blotto game has also experienced a recent resurgence of interest (see, for example, Golman and Page 2009; Hart 2008; Kovenock and Roberson 2008a, 2009; Kvasov 2007; Laslier 2002; Laslier and Picard 2002; Roberson 2006, 2008; Weinstein 2005). One of the primary appeals of the Colonel Blotto game is that it provides a unified theoretical framework that sheds light on a host of important issues in a broad set of environments. Most of the models examined in this chapter may be viewed as variants and extensions of Borel's original theme.

We focus on conflicts in which the payoff to each of two risk-neutral players is given by the difference between an "objective" function — which aggregates the outcomes (wins or losses) in the individual component contests into the total benefit from engaging in the conflict and a cost function — which aggregates the efforts allocated to the individual component contests into a total cost of effort for the conflict. We divide our analysis into two parts corresponding to whether the linkages across battlefields arise through the aggregation of battlefield outcomes (objective-side linkages) or in the aggregation of battlefield costs (costside linkages). On the cost side we examine structural linkages such as budget constraints and investments which provide a uniform level of force across all of the component contests, which we call "infrastructure investments." On the objective side we examine several objectives in which the benefit from engaging in the conflict is measured by some function of the sum of the values of battlefields won. This includes objectives which measure the benefit as the sum itself, as well as objectives in which a positive benefit accrues only if the sum reaches some critical value, for example half the total value at stake.

In addition to breaking down our analysis according to the nature of the linkages across contests, we also divide the analysis according to the type of contest success function (CSF) employed in each battlefield contest. The CSF maps the players' resource expenditures in a contest into their respective probabilities of winning the contest. We focus on two types of CSFs, chosen both because of their prominence in the literature and the contrasting emphasis each places on the role of random noise in determining the contest outcome. Under the auction contest success function the player with the larger resource expenditure within the battlefield wins the battlefield with certainty. Under the lottery contest success function the probability that a player wins the battlefield is equal to the ratio of the player's resource expenditure to the sum of the players' expenditures within the battlefield.

The auction CSF may be viewed as capturing environments in which random noise plays 
little role in determining the contest outcome. Alternatively, it may be viewed as representing a modeling strategy in which all factors influencing the contest outcome are captured in the model and unmodeled factors play little or no role. Because the auction CSF is discontinuous when players have the same expenditure, small differences in resources expended may lead to large differences in the probability of winning. The auction CSF thereby represents cutthroat competition in sunk expenditure. In single battlefield contests employing the auction CSF generally leads to the nonexistence of pure strategy Nash equilibrium and requires nondegenerate mixed strategies in equilibrium. Our analysis shows that this feature of contests with the auction CSF carries over to multibattlefield contests, where mixed strategies are multivariate joint distribution functions. In examining such strategies, we focus attention on both the randomization in resources allocated to each battlefield and how structural linkages across battlefields lead to behavioral linkages in the form of endogenous correlation structures in the players' joint distributions.

The lottery CSF is perhaps the most popular method for modeling single battlefield contests. Under the lottery CSF expenditure by the two players may be interpreted as the purchase of lottery tickets, where a random draw from the outstanding tickets determines the winner. One consequence of the random noise that persists conditional on the players' expenditures is that under the lottery CSF competition is softened relative to the auction CSF. Under standard cost assumptions, the lottery CSF yields a concave payoff function in single battlefield contests leading, in turn, to the existence of Nash equilibrium in pure strategies. Our analysis shows that this feature of contests with the lottery CSF generally carries over to multibattlefield conflicts. However, there are examples of structural linkages that generate nonquasiconcave objectives and therefore require mixed strategies in equilibrium.

Section 2 introduces the formal framework used in this chapter. This includes the specification of payoffs in terms of objective functions and cost functions and the determination of battlefield outcomes. Our treatment of the objective and cost functions includes an outline of the structural linkages that are the focus of our analysis. Section 3 examines the behavioral linkages arising from cost-side linkages, and Section 4 examines the behavioral linkages arising from objective-side linkages. Section 5 concludes by discussing extensions and pointing to areas for future research, including alternative contest success functions, n-player versions of the models, incomplete information, dynamics, and empirical evaluation. 


\section{Conflict with Multiple Battlefields}

Consider two players, $A$ and $B$, competing in a conflict consisting of $n$ battlefields. The two players simultaneously expend nonnegative $n$-tuples of a (sunk) resource, $\mathbf{x}_{i}=\left(x_{i, 1}, \ldots, x_{i, n}\right)$, $i \in\{A, B\}$, where $x_{i, j}$ is the allocation of the resource (or allocation of force) by player $i$ to battlefield $j$. If the two players allocate $x_{A, j}$ and $x_{B, j}$ to battlefield $j$, then each player's outcome in battlefield $j, v_{i, j}\left(x_{i, j}, x_{-i, j}, \widetilde{\omega}_{j}\right), i \in\{A, B\}$, is a real-valued function of the allocations $\left(x_{A, j}, x_{B, j}\right)$ and the realization of a real-valued random variable $\widetilde{\omega}_{j}$, where it is assumed that the random variables $\widetilde{\omega}_{1}, \widetilde{\omega}_{2}, \ldots, \widetilde{\omega}_{n}$ are independent. The total benefit to player $i$ from engaging in the multi-battlefield conflict is assumed to be a real-valued function of the player's respective battlefield outcomes, $v_{i}\left(v_{i, 1}\left(x_{i, 1}, x_{-i, 1}, \widetilde{\omega}_{1}\right), \ldots, v_{i, n}\left(x_{i, n}, x_{-i, n}, \widetilde{\omega}_{n}\right)\right)$, which we call player $i$ 's objective function. The cost of player $i$ 's vector of expenditures is given by $c_{i}\left(\mathbf{x}_{i}\right)$. We assume that each player is a risk neutral expected payoff maximizer and that the expected payoff of an arbitrary player $A$ is the expected benefit minus the cost: ${ }^{1}$

$$
\begin{aligned}
U_{A}\left(\mathbf{x}_{A}, \mathbf{x}_{B}\right) & \equiv E\left(v_{A}\left(v_{A, 1}\left(x_{A, 1}, x_{B, 1}, \widetilde{\omega}_{1}\right), \ldots, v_{A, n}\left(x_{A, n}, x_{B, n}, \widetilde{\omega}_{n}\right)\right)\right)-c_{A}\left(\mathbf{x}_{A}\right) \\
& =V_{A}\left(\mathbf{x}_{A}, \mathbf{x}_{B}\right)-c_{A}\left(\mathbf{x}_{A}\right)
\end{aligned}
$$

Before investigating the linkages across battlefields that arise from the objective and cost functions, we first examine the determination of battlefield outcomes.

\subsection{Battlefield Outcomes}

The focus of this chapter is on conflicts comprised of battlefields that are winner-take-all contests. That is, for any given $\left(x_{A, j}, x_{B, j}, \omega_{j}\right)$ exactly one of the two players "wins" the battlefield and the other "loses," with battlefield outcomes that are explicitly dependent on the event of winning or losing. As described below we focus on a formulation of the contest in which, for any given $\left(x_{A, j}, x_{B, j}\right)$ pair, the value of the random variable $\widetilde{\omega}_{j}$ determines only the identity of the winner, and not the values of the battlefield contingent on winning or losing. In this formulation, $\left(x_{i, j}, x_{-i, j}, \omega_{j}\right) \in \mathcal{W}_{i, j}\left(\mathcal{W}_{-i, j}\right)$ indicates that given the resource levels $x_{i, j}$ and $x_{-i, j}$ and the realization $\omega_{j}$ of the random varible $\widetilde{\omega}_{j}$ player $i(-i)$ is the winner (and therefore player $-i(i)$ the loser) in battlefield $j$. Within component contest $j$, we may

\footnotetext{
${ }^{1}$ If the players are not risk neutral, an arbitrary player $A$ would maximize a nonaffine function of $v_{A}\left(v_{A, 1}\left(x_{A, 1}, x_{B, 1}, \widetilde{\omega}_{1}\right), \ldots, v_{A, n}\left(x_{A, n}, x_{B, n}, \widetilde{\omega}_{n}\right)\right)-c_{A}\left(\mathbf{x}_{A}\right)$, and payoffs would no longer be separable in the objective and cost. This creates a different, but interesting, set of behavioral linkages across battlefields that are not examined in this chapter.
} 
define $p_{A, j}\left(x_{A, j}, x_{B, j}\right)=\operatorname{Pr}\left(\left(x_{A, j}, x_{B, j}, \omega_{j}\right) \in \mathcal{W}_{A, j}\right)$ to be the probability that player $A$ wins the component contest $j$ conditional on the two players' expenditures in the contest and $p_{B, j}\left(x_{A, j}, x_{B, j}\right)=1-p_{A, j}\left(x_{A, j}, x_{B, j}\right)$ to be the corresponding probability that player $B$ wins the component contest. Consistent with popular usage, we will refer to $p_{i, j}\left(x_{A, j}, x_{B, j}\right)$ as the contest success function for battlefield $j$.

In the sections that follow we will restrict ourselves to independent random variables $\widetilde{\omega}_{1}, \widetilde{\omega}_{2}, \ldots, \widetilde{\omega}_{n}$ which generate one of the following two contest success functions (commonly known as the "auction" and "lottery" contest success functions), independently across each battlefield:

(i) Under the auction contest success function ${ }^{2}$

$$
p_{A, j}\left(x_{A, j}, x_{B, j}\right)=\left\{\begin{array}{ccc}
1 & \text { if } & x_{A, j}>x_{B, j} \\
I_{C} & \text { if } & x_{A, j}=x_{B, j} \\
0 & \text { if } & x_{A, j}<x_{B, j}
\end{array}\right.
$$

(ii) Under the lottery contest success function

$$
p_{A, j}\left(x_{A, j}, x_{B, j}\right)=\left\{\begin{array}{cl}
\frac{x_{A, j}}{x_{A, j}+x_{B, j}} & \text { if }\left(x_{A, j}, x_{B, j}\right) \neq(0,0) \\
\frac{1}{2} & \text { if }\left(x_{A, j}, x_{B, j}\right)=(0,0)
\end{array}\right.
$$

For each player $i \in\{A, B\}$ we attach to each battlefield $j$ a battlefield specific value to winning, $w_{i, j}>0$, and a battlefield specific value to losing, $l_{i, j}$, that are independent of the expenditures $\left(x_{A, j}, x_{B, j}\right)$ and the realized value of $\omega_{j}$. To facilitate the exposition, we further assume that $l_{i, 1}=\ldots=l_{i, n}=0$, so that $v_{A, j}\left(x_{A, j}, x_{B, j}, \omega_{j}\right)$ takes on a value 0 or $w_{A, j}>0$. We may therefore write

$$
v_{A, j}\left(x_{A, j}, x_{B, j}, \omega_{j}\right)=\left\{\begin{array}{cl}
w_{A, j} & \text { if }\left(x_{A, j}, x_{B, j}, \omega_{j}\right) \in \mathcal{W}_{A, j} \\
0 & \text { if }\left(x_{A, j}, x_{B, j}, \omega_{j}\right) \notin \mathcal{W}_{A, j}
\end{array}\right.
$$

\subsection{Objective Functions}

When analyzing the aggregation of battlefield outcomes we examine count objectives — that is, objectives for which the total benefit from the overall conflict is measured by some function of the sum of the values of battlefields won. More formally, let $I_{\left\{\left(x_{A, j}, x_{B, j}, \omega_{j}\right) \in \mathcal{W}_{A, j}\right\}}$ denote

\footnotetext{
${ }^{2} I_{c}$ in this formulation refers to an indicator that depends on the particular model of conflict being examined. Often, in games with discontinuous payoffs, such as winner-take-all contests with an auction contest success function, the modeler must employ a judicious choice of a tie-breaking rule in order to avoid having to revert to the use of $\varepsilon$-equilibrium concepts.
} 
the indicator function that takes the value 1 if player $A$ is a winner, $\left(x_{A, j}, x_{B, j}, \omega_{j}\right) \in \mathcal{W}_{A, j}$, and 0 otherwise. Player $A$ is said to have a count objective if there exists a function $f$ such that for every $n$-tuple of battlefield outcomes $\left(v_{A, 1}\left(x_{A, 1}, x_{B, 1}, \omega_{1}\right), \ldots, v_{A, n}\left(x_{A, n}, x_{B, n}, \omega_{n}\right)\right)$

$$
v_{A}\left(v_{A, 1}\left(x_{A, 1}, x_{B, 1}, \omega_{1}\right), \ldots, v_{A, n}\left(x_{A, n}, x_{B, n}, \omega_{n}\right)\right) \equiv f\left(\sum_{i=1}^{n} w_{A, j} I_{\left\{\left(x_{A, j}, x_{B, j}, \omega_{j}\right) \in \mathcal{W}_{A, j}\right\}}\right)
$$

There are two prominent types of count objectives that will be examined in this chapter, the linear count objective and the critical-value count objective. Under a linear count objective, $f$ is the identity:

$$
v_{A}\left(v_{A, 1}\left(x_{A, 1}, x_{B, 1}, \omega_{1}\right), \ldots, v_{A, n}\left(x_{A, n}, x_{B, n}, \omega_{n}\right)\right)=\sum_{i=1}^{n} w_{A, j} I_{\left\{\left(x_{A, j}, x_{B, j}, \omega_{j}\right) \in \mathcal{W}_{A, j}\right\}} .
$$

In this formulation, a player maximizes the expected sum of the values of battlefields won minus the cost of expenditures. Under a critical-value count objective,

$$
v_{A}\left(v_{A, 1}\left(x_{A, 1}, x_{B, 1}, \omega_{1}\right), \ldots, v_{A, n}\left(x_{A, n}, x_{B, n}, \omega_{n}\right)\right)= \begin{cases}w_{A} & \text { if } \sum_{i=1}^{n} w_{A, j} I_{\left\{\left(x_{A, j}, x_{B, j}, \omega_{j}\right) \in \mathcal{W}_{A, j}\right\}} \geq m_{A} \\ 0 & \text { otherwise }\end{cases}
$$

In this case, if the sum of the values of the battlefields that player $A$ wins is at least $m_{A}$, then he earns a constant $w_{A}>0$ before netting out the cost of all expenditures. Otherwise, player $A$ earns nothing and loses his costs.

We will often focus on the case in which all battlefields won are of equal individual value, normalized to 1 , i.e. $w_{A, 1}=\ldots=w_{A, n}=1$. Under this normalization, the sum of the values of battlefields won is equal to the number of battlefields won, $\sum_{i=1}^{n} w_{A, j} I_{\left\{\left(x_{A, j}, x_{B, j}, \omega_{j}\right) \in \mathcal{W}_{A, j}\right\}}=$ $\sum_{i=1}^{n} I_{\left\{\left(x_{A, j}, x_{B, j}, \omega_{j}\right) \in \mathcal{W}_{A, j}\right\}}$. A count objective satisfying this restriction is labeled a pure-count objective, and the two types of count objectives given in equations (2) and (3) are referred to as the linear pure-count objective and the critical-value pure-count objective respectively.

Three special cases of critical-value pure-count objectives that are examined in this chapter are the cases of a majoritarian objective, where, for $n$ odd, $m_{A}=\frac{n}{2}$, a weakest-link objective, where $m_{A}=n$, and a best-shot objective where $m_{A}=1$.

It should be emphasized that the models we examine will generally feature some type of count objective, but these may or may not be identical across the two players. So, for instance, in the next two sections we will examine games in which (i) both players have 
linear count or linear pure-count objectives, (ii) both players have majoritarian objectives, and (iii) one player has a weakest-link objective and the other a best-shot objective.

\subsection{Cost Functions}

In the multi-battlefield conflicts that we examine, the cost function $c_{A}\left(\mathbf{x}_{A}\right)$ may or may not be additively separable in battlefield expenditures. If the function is additively separable, it takes the form $c_{A}\left(\mathbf{x}_{A}\right)=c_{A, 1}\left(x_{A, 1}\right)+\ldots+c_{A, n}\left(x_{A, n}\right)$, where the total cost of the allocation $\mathbf{x}_{A}$ is the sum of the costs of the battlefield specific allocations. One special case that will be used in the continuation is the case of identical battlefield specific cost functions of a linear form, $c_{A}\left(\mathbf{x}_{A}\right)=c \cdot\left(x_{A, 1}+\ldots+x_{A, n}\right)$, where $c>0$. We refer to this as the case of linear costs. Two types of nonseparable cost functions will be employed in the following sections. One is the case of a linear technology up to an overall budget constraint, which we term budget-constrained linear costs,

$$
c_{A}\left(\mathbf{x}_{A}\right)= \begin{cases}c \cdot\left(x_{A, 1}+\ldots+x_{A, n}\right) & \text { if }\left(x_{A, 1}+\ldots+x_{A, n}\right) \leq \mathcal{B}_{A} \\ \infty & \left(x_{A, 1}+\ldots+x_{A, n}\right)>\mathcal{B}_{A}\end{cases}
$$

Here, $\mathcal{B}_{A}$ has the interpretation of a resource or budget constraint on a one dimensional resource that is allocated across the $n$ battlefields, where this resource has a constant opportunity cost of use elsewhere of $c$. A special case used in the classical Colonel Blotto game is the case where each unit of the resource up to the budget constraint has a zero opportunity cost, $c=0$, so that the resource budget is use-it-or-lose-it. We refer to this case as budget-constrained use-it-or-lose-it costs.

The second nonseparable cost function that will be examined is the case of a multibattlefield cost function arising from the inclusion of an infrastructure investment. By infrastructure investment, we mean a nontargetable technology that provides a uniform allocation of a resource across all battlefields. A natural way to think of such an investment is as one that is a "public good" in the sense that it provides an input of the resource that is nonrival across all battlefields. For instance, in a military setting, a fixed investment in an innovative weapons system or a high-tech command and control center may be applied across all battlefields simultaneously at the same cost that it might be applied to a subset of battlefields.

In our treatment, we assume that the resource corresponding to an investment in infrastructure serves as a perfect substitute for the targetable resource in each battlefield. This 
assumption allows us to treat the sum of player $i$ 's infrastructure investment and his targeted resource to a given battlefield $j$ as a single choice variable $\widehat{x}_{i, j}$, which we call player $i$ 's effective force allocation to battlefield $j$. It is this allocation that enters into the contest success function for that battlefield.

If in addition the (constant) per unit cost, $c_{u}$, of the infrastructure investment is less than the cost per unit, $n c$, of allocating the targetable resource uniformly across all $n$ battlefields, cost minimization implies that we can write the cost function as:

$$
c_{A}\left(\widehat{\mathbf{x}}_{A}\right)=c \cdot\left(\left(\widehat{x}_{A, 1}-\min _{j} \widehat{x}_{A, j}\right)+\ldots+\left(\widehat{x}_{A, n}-\min _{j} \widehat{x}_{A, j}\right)\right)+c_{u} \cdot \min _{j} \widehat{x}_{A, j} .
$$

As is clear from the formulation, it is cost minimizing to employ the infrastructure investment to provide all units up to the minimum effective force allocation across battlefields, with the difference between this minimum effective force allocation and the allocation in any other given battlefield being met by the targetable resource. We refer to this case as infrastructure costs. $^{3}$

\subsection{Multi-Battle Conflict with Structural Linkages}

Before outlining the structural linkages examined in this chapter, it is useful to make the following straightforward observation: If each player $i=A, B$ has a linear count objective and an additively separable cost function, then each player $i$ 's expected payoff may be written as $\left[E v_{i, 1}\left(x_{i, 1}, x_{-i, 1}, \omega_{1}\right)-c_{i, 1}\left(x_{i, 1}\right)\right]+\ldots+\left[E v_{i, n}\left(x_{i, n}, x_{-i, n}, \omega_{n}\right)-c_{i, n}\left(x_{i, n}\right)\right]$. In this case, maximizing the expected payoff in the overall conflict is equivalent to maximizing the expected payoff in each battlefield contest separately, $E v_{i, j}\left(x_{i, j}, x_{-i, j}, \omega_{j}\right)-c_{i, j}\left(x_{i, j}\right)$, $j=1, . ., n$. Solving for a Nash equilibrium in the multi-battlefield conflict reduces to the simultaneous solution of $n$ independent single-input winner-take-all contests. Lemma 1 states this formally.

Lemma 1. If each player $i=A, B$ has a linear count objective and an additively separable cost function then maximizing the expected payoff for the overall conflict, given in equation (1), is equivalent to maximizing the expected payoff, $E v_{i, j}\left(x_{i, j}, x_{-i, j}, \omega_{j}\right)-c_{i, j}\left(x_{i, j}\right)$, in each battlefield contest separately.

In the pages that follow, we detail the intricate linkages between contests that arise in

\footnotetext{
${ }^{3}$ Because an infrastructure investment, by definition, raises all battlefield allocations by the amount of the investment, the existence of a cost efficient infrastructure investment yields a cost function which may be decreasing over regions of the domain of battlefield allocations.
} 
cases where either there is a deviation from the assumption of a linear count objective or the cost function is not additively separable. The layout of this chapter is as follows. In section 3 we examine cost-side linkages in games with linear count and pure-count objectives and nonseperable cost functions. Subsection 3.1 examines the behavioral linkages arising from a budget-constrained use-it-or-lose-it cost function. Under the auction CSF, the combination of a linear pure-count objective and symmetric budget-constrained use-it-or-lose-it costs yields the classic Colonel Blotto game due to Borel. Extensions of this model to the case of asymmetric budget constraints (Roberson 2006) and, in subsection 3.2, budget-constrained linear costs (Kvasov 2007, Roberson and Kvasov 2008) are treated. We also present a class of models, due to Friedman (1958) and Robson (2005), that address the same issues but employ the lottery contest success function in each component contest. We end the section by examining the case of an infrastructure investment.

In section 4 we investigate objective-side linkages. In subsection 4.1 we examine the majoritarian objective with linear costs and briefly discuss the case of budget-constrained use-it-or-lose-it costs. An approach to this problem with a generalization of the lottery contest success function and a linear cost function is examined by Snyder (1989) and Klumpp and Polborn (2006). The problem of a majoritarian objective assuming an auction contest success function and budget-constrained use-it-or-lose-it costs was first addressed by Borel and Ville (1938), who examine the case of three battlefields. ${ }^{4}$ Szentes and Rosenthal (2003a) solve for an equilibrium under a majoritarian objective with three battlefields and linear costs, and Szentes and Rosenthal (2003b) examine equilibria of games with more than three battlefields and linear costs in which players must achieve the same supermajority of battlefield victories.

Subsection 4.2 looks at the case in which one of the players has a best-shot objective and his opponent a weakest-link objective. For the lottery contest success function, an equilibrium for this case is provided by Clark and Konrad (2007). For the auction contest success function, an equilibrium (in nondegenerate mixed strategies) and properties satisfied by any equilibrium are provided by Kovenock and Roberson (2009). In subsection 4.3, we briefly examine extensions in which the expenditure of resources across multiple battlefields contributes to the construction of aggregate measures of resource allocation that map the vector of battlefield allocations to the real line. Success or failure in the conflict is then a (potentially stochastic) function of the two players' aggregate measures.

\footnotetext{
${ }^{4}$ See also Laslier (2003) who allows the three battlefields to have different weights.
} 


\section{Multiple Battlefields with Cost Linkages}

We begin in section 3.1 with linear count and pure-count objectives and examine the linkages that arise from budget-constrained use-it-or-lose-it costs. In section 3.2 we extend the analysis to budget-constrained linear costs and, in section 3.3, infrastructure costs.

\subsection{Budget-Constrained Use-It-Or-Lose-It Costs}

Borel's Colonel Blotto game - an auction battlefield contest success function, linear purecount objective, and budget-constrained use-it-or-lose-it costs - highlights the nature of the battlefield linkages arising from a constraint on the sum of additively separable battlefield expenditures. In the Colonel Blotto game each of the two players has a resource constraint (or budget). Let $\mathrm{A}$ denote the strong player with resource constraint $\mathcal{B}_{A}$, and $\mathrm{B}$ denote the weak player with resource constraint $\mathcal{B}_{B}$, where $\mathcal{B}_{A} \geq \mathcal{B}_{B}$. For player $i$, the set of feasible force allocations across the $n$ battlefields is denoted by

$$
\mathcal{S}_{i}=\left\{\mathrm{x} \in \mathbb{R}_{+}^{n} \mid \sum_{j=1}^{n} x_{i, j} \leq \mathcal{B}_{i}\right\}
$$

Although, Theorem 1 below can be extended to allow for heterogenous battlefield valuations, ${ }^{5}$ we will focus on the simplest case in which all battlefields are of equal individual value, normalized to 1 (i.e., $w_{i, j}=1$ for $i=A, B$ and all $j$ ). The total value of battlefields contested in the Colonel Blotto game is then $n$. Each player's objective is to maximize the expected number of individual battlefields won.

In each battlefield, or component contest, $j$, the probability that player $i$ wins battlefield $j$ with an allocation of force $x_{i, j}$ when player $-i$ allocates $x_{-i, j}$ units of force is determined by the auction CSF. Consequently, for any feasible $n$-tuple of force allocations $\mathbf{x}_{i} \in \mathcal{S}_{i}$, player $i$ 's expected payoff is given by

$$
U_{i}\left(\mathbf{x}_{A}, \mathbf{x}_{B}\right)=\sum_{j=1}^{n} p_{i, j}\left(x_{A, j}, x_{B, j}\right)
$$

where $p_{i, j}\left(x_{A, j}, x_{B, j}\right)$ denotes the auction CSF.

\footnotetext{
${ }^{5}$ For the case of symmetric resource constraints, $\mathcal{B}_{A}=\mathcal{B}_{B}$, see Laslier (2002). For asymmetric resource constraints $\left(\mathcal{B}_{A}>\mathcal{B}_{B}\right)$ Theorem 1 can be extended to allow the battlefield valuations to vary across the individual component contests as long as for each distinct battlefield valuation there are at least three battlefields with that valuation.
} 
If the strong player (A) has sufficient resources to outbid the weaker player's (B's) maximal force allocation on all $n$ battlefields (i.e., if $\mathcal{B}_{A} \geq n \mathcal{B}_{B}$ ) then there, trivially, exists a pure strategy equilibrium, and the strong player $(\mathrm{A})$ wins all of the battlefields. ${ }^{6}$ It is well known that for the remaining parameter configurations, $(1 / n) \mathcal{B}_{A}<\mathcal{B}_{B} \leq \mathcal{B}_{A}$, there is no pure strategy equilibrium for this class of games. A mixed strategy, which we term a distribution of force, for player $i$ is an $n$-variate distribution function $P_{i}: \mathbb{R}_{+}^{n} \rightarrow[0,1]$ with support (denoted $\operatorname{Supp}\left(P_{i}\right)$ ) contained in player $i$ 's set of feasible force allocations $\mathcal{S}_{i}$ and with the set of one-dimensional marginal distribution functions $\left\{F_{i, j}\right\}_{j=1}^{n}$, one univariate marginal distribution function for each battlefield $j$. The $n$-tuple of player $i$ 's allocation of force to each of the $n$ battlefields is a random n-tuple drawn from the $n$-variate distribution function $P_{i}$.

\section{Optimal Strategies}

Theorem 1 summarizes Roberson's (2006) characterization of equilibrium in the Colonel Blotto game in the case that $n \geq 3$ and $\mathcal{B}_{B} / \mathcal{B}_{A}$ satisfies $(2 / n)<\left(\mathcal{B}_{B} / \mathcal{B}_{A}\right) \leq 1$. See Roberson (2006) for the remaining case with $n \geq 3$ and $(1 / n)<\left(\mathcal{B}_{B} / \mathcal{B}_{A}\right) \leq(2 / n)$. The case of $n=2$ is dealt with in Gross and Wagner (1950) and Macdonell and Mastronardi (2009). The following result holds for a range of tie-breaking rules, including fair randomization $\left(I_{C}=(1 / 2)\right)$.

Theorem 1 (Roberson (2006)). If $n \geq 3$ and $\mathcal{B}_{B} / \mathcal{B}_{A}$ satisfies $(2 / n)<\left(\mathcal{B}_{B} / \mathcal{B}_{A}\right) \leq 1$, then the pair of $n$-variate distribution functions $P_{A}^{*}$ and $P_{B}^{*}$ constitutes a Nash equilibrium of the Colonel Blotto game (i.e., auction CSF, linear pure-count objective, and budget-constrained use-it-or-lose-it costs) if and only if it satisfies the following two conditions: (1) For each player $i, \operatorname{Supp}\left(P_{i}^{*}\right) \subseteq \mathcal{S}_{i}$ and (2) $P_{i}^{*}, i=A, B$, provide the corresponding unique set of univariate marginal distribution functions $\left\{F_{i, j}^{*}\right\}_{j=1}^{n}$ outlined below.

$$
\begin{gathered}
\forall j \in\{1, \ldots, n\} \quad F_{B, j}^{*}(x)=\left(1-\frac{\mathcal{B}_{B}}{\mathcal{B}_{A}}\right)+\frac{x}{\frac{2}{n} \mathcal{B}_{A}}\left(\frac{\mathcal{B}_{B}}{\mathcal{B}_{A}}\right) \quad \text { for } \quad x \in\left[0, \frac{2}{n} \mathcal{B}_{A}\right] . \\
\forall j \in\{1, \ldots, n\} \quad F_{A, j}^{*}(x)=\frac{x}{\frac{2}{n} \mathcal{B}_{A}} \quad \text { for } \quad x \in\left[0, \frac{2}{n} \mathcal{B}_{A}\right] .
\end{gathered}
$$

Moreover, such strategies exist, and in any Nash equilibrium the expected payoff of the weak player $(B)$ is $n\left(\mathcal{B}_{B} / 2 \mathcal{B}_{A}\right)$ and the expected payoff of the strong player $(A)$ is $n-n\left(\mathcal{B}_{B} / 2 \mathcal{B}_{A}\right)$.

\footnotetext{
${ }^{6}$ When $\mathcal{B}_{A}=n \mathcal{B}_{B}$, in each battlefield we must employ a tie-breaking rule that selects the stronger player (A).
} 
For a proof of Theorem 1 see Roberson (2006). A major part of this proof is establishing the existence of a pair of $n$-variate distributions $P_{A}^{*}$ and $P_{B}^{*}$ with the prescribed univariate marginal distribution functions and with supports contained in the feasible sets of force allocations, $\mathcal{S}_{A}$ and $\mathcal{S}_{B}$ respectively. Note that uniqueness of the equilibrium expected payoffs follows immediately from the fact that the Colonel Blotto game is constant-sum.

In the Colonel Blotto game the primary linkage is an implicit opportunity cost that arises from the fact that resources which are used in one particular battlefield cannot be used in any of the other battlefields. As a result, even though resources are use-it-or-lose-it, the implicit opportunity costs create incentives that behave much like linear costs. In fact, if $\mathcal{B}_{B} / \mathcal{B}_{A}$ satisfies $(2 / n)<\left(\mathcal{B}_{B} / \mathcal{B}_{A}\right) \leq 1$, then the unique set of univariate marginal distributions in the Colonel Blotto game corresponds to the unique set of univariate marginal distributions in a game with two unconstrained-budget players and a set of $n$ independent all-pay auctions, where each auction has value $(2 / n) \mathcal{B}_{A}$ for player $B$ and value $(2 / n)\left(\mathcal{B}_{A}^{2} / \mathcal{B}_{B}\right)$ for player $A$.

Another distinctive feature of the equilibria in the asymmetric Colonel Blotto game is that the disadvantaged player uses a "guerrilla warfare" strategy which involves the stochastic allocation of zero forces to a subset of the battlefields. Conversely, the player with the larger budget plays a "stochastic complete coverage" strategy that stochastically allocates forces across all battlefields, with each battlefield receiving a strictly positive level of forces with probability one. This feature does not arise under the corresponding game with battlefield outcomes determined by the lottery CSF.

Friedman (1958) analyzes a Blotto-type game which replaces the auction CSF, of the original Colonel Blotto game, with the lottery $\mathrm{CSF}^{7}$ and replaces the linear pure-count objective with a linear count objective and common but heterogeneous battlefield valuations $\left\{v_{j}\right\}_{j=1}^{n}$ (i.e., $w_{i, j}=v_{j}$ for $i=A, B$ and all $j$ ). That is, Friedman's Blotto-type game consists of: (i) the lottery component contest success function, (ii) a linear count objective function with heterogenous battlefield valuations $\left\{v_{j}\right\}_{j=1}^{n}$ that are symmetric across players, and (iii) budget-constrained use-it-or-lose-it costs with resource constraints $\mathcal{B}_{A}$ and $\mathcal{B}_{B}$. Theorem 2 provides Friedman's characterization of equilibrium in this Blotto-type game.

Theorem 2 (Friedman (1958)). The pair of $n$-tuples $\mathbf{x}_{A}^{*}$ and $\mathbf{x}_{B}^{*}$ constitutes a Nash equilibrium of the Blotto-type game with the lottery CSF, heterogenous battlefield valuations $\left\{v_{j}\right\}_{j=1}^{n}$,

\footnotetext{
${ }^{7}$ See also Robson (2005) who examines this environment under a wider range of Tullock CSFs of the form $p_{i}\left(x_{i, j}, x_{-i, j}\right)=x_{i, j}^{r} /\left(x_{i, j}^{r}+x_{-i, j}^{r}\right)$ for $r \in(0,1]$.
} 
and budget-constrained use-it-or-lose-it costs with resource constraints $\mathcal{B}_{A}$ and $\mathcal{B}_{B}$, if

$$
\forall j \in\{1, \ldots, n\} \quad x_{A, j}^{*}=\left(\mathcal{B}_{A}\right) \frac{v_{j}}{\sum_{j^{\prime}=1}^{n} v_{j^{\prime}}} \quad \text { and } \quad x_{B, j}^{*}=\left(\mathcal{B}_{B}\right) \frac{v_{j}}{\sum_{j^{\prime}=1}^{n} v_{j^{\prime}}} .
$$

The equilibrium expected payoffs are $\left(\mathcal{B}_{B} /\left(\mathcal{B}_{A}+\mathcal{B}_{B}\right)\right) \sum_{j=1}^{n} v_{j}$ for the weak player $(B)$, and $\left(\mathcal{B}_{A} /\left(\mathcal{B}_{A}+\mathcal{B}_{B}\right)\right) \sum_{j=1}^{n} v_{j}$ for the strong player $(A)$.

In the Blotto-type game with lottery CSF, an implicit opportunity cost linkage arises and each player uses a "deterministic complete coverage" strategy that proportionally allocates forces based on the relative values of the battlefields. Robson (2005) shows that if the lottery CSF is replaced by the variation of the Tullock CSF examined in Skaperdas and Syropoulos (1998), then there may exist "non-participation equilibria" in which one or both players deterministically drop out of a subset of the battlefields. Note, though, that this deterministic non-participation strategy is qualitatively different from the stochastic guerilla warfare strategy employed by the weaker player in the Colonel Blotto game, in which (only) the weaker player stochastically allocates zero forces to a subset of the battlefields.

\subsection{Budget-Constrained Linear Costs}

The classic constant-sum formulation of the Colonel Blotto game provides an important benchmark in the study of strategic multi-dimensional conflict. In this formulation, any unused resources have no value. Kvasov (2007) introduces a non-constant-sum version of the two-player Colonel Blotto game that relaxes the use-it-or-lose-it feature of the original formulation and, for the case of symmetric resource endowments, finds that there is a one-toone mapping from the unique set of equilibrium univariate marginal distribution functions in the constant-sum game to those in the non-constant-sum game. Roberson and Kvasov (2008) extend this analysis to the case of asymmetric resource endowments and find that as long as the level of asymmetry between the players' budgets is below a threshold - this relationship between the constant-sum and non-constant-sum games is preserved.

In the taxonomy of section 2, the non-constant-sum formulation of the Colonel Blotto game utilizes the auction component contest success function, a linear count objective with $n$ homogenous battlefields of common value $v$ (i.e., $w_{i, j}=v$ for $i=A, B$ and all $j$ ), budgetconstrained linear costs with $c=1$ and resource constraints $\mathcal{B}_{A}$ and $\mathcal{B}_{B}, \mathcal{B}_{A} \geq \mathcal{B}_{B}$.

Let $\widehat{\mathcal{B}}_{i}: \mathbb{R}_{+}^{4} \rightarrow \mathbb{R}$ denote player $i$ 's modified resource constraint, given by

$$
\widehat{\mathcal{B}}_{B}\left(\mathcal{B}_{A}, \mathcal{B}_{B}, v, n\right)=\min \left\{\mathcal{B}_{B}, \frac{n v}{2}\right\}
$$


for player B, and

$$
\widehat{\mathcal{B}}_{A}\left(\mathcal{B}_{A}, \mathcal{B}_{B}, v, n\right)=\min \left\{\mathcal{B}_{A}, \frac{n v}{2},\left(\frac{n v \mathcal{B}_{B}}{2}\right)^{1 / 2}\right\}
$$

for player A. Clearly, $\mathcal{B}_{A} \geq \mathcal{B}_{B}$ implies $\widehat{\mathcal{B}}_{A} \geq \widehat{\mathcal{B}}_{B}$. In the case that $\widehat{\mathcal{B}}_{B} / \widehat{\mathcal{B}}_{A}$ satisfies $(2 / n)<$ $\left(\widehat{\mathcal{B}}_{B} / \widehat{\mathcal{B}}_{A}\right) \leq 1$, a modified statement of Theorem 1 - in which each player $i$ 's resource constraint $\mathcal{B}_{i}$ is replaced with his modified resource constraint $\widehat{\mathcal{B}}_{i}-$ applies. That is, for $(2 / n)<\left(\widehat{\mathcal{B}}_{B} / \widehat{\mathcal{B}}_{A}\right) \leq 1$ any equilibrium of the constant-sum Colonel Blotto game with $n$ battlefields and resource constraints $\widehat{\mathcal{B}}_{A}\left(\mathcal{B}_{A}, \mathcal{B}_{B}, v, n\right)$ and $\widehat{\mathcal{B}}_{B}\left(\mathcal{B}_{A}, \mathcal{B}_{B}, v, n\right)$ is an equilibrium of the non-constant-sum Colonel Blotto game with $n$ battlefields of common value $v$ and resource constraints $\mathcal{B}_{A}$ and $\mathcal{B}_{B}$. See Roberson and Kvasov (2008) for the remaining case where $\left(\widehat{\mathcal{B}}_{B} / \widehat{\mathcal{B}}_{A}\right) \leq(2 / n)$.

Theorem 3 (Roberson and Kvasov (2008)). If $n \geq 3$ and $\widehat{\mathcal{B}}_{B} / \widehat{\mathcal{B}}_{A}$ satisfies $(2 / n)<$ $\left(\widehat{\mathcal{B}}_{B} / \widehat{\mathcal{B}}_{A}\right) \leq 1$, then the pair of $n$-variate distribution functions $P_{A}^{*}$ and $P_{B}^{*}$ constitutes a Nash equilibrium of the non-constant-sum Colonel Blotto game (i.e., auction CSF, linear count objective with common battlefield value $v$, and budget-constrained linear costs with $c=1$ and resource constraints $\mathcal{B}_{A}$ and $\mathcal{B}_{B}$ ) if and only if it satisfies the following two conditions: (1) For each player $i, \operatorname{Supp}\left(P_{i}^{*}\right) \subseteq \mathcal{S}_{i}$ and (2) $P_{i}^{*}, i=A, B$, generates the corresponding unique set of univariate marginal distribution functions $\left\{F_{i, j}^{*}\right\}_{j=1}^{n}$ outlined below.

$$
\begin{gathered}
\forall j \in\{1, \ldots, n\} \quad F_{B, j}^{*}(x)=\left(1-\frac{\widehat{\mathcal{B}}_{B}}{\widehat{\mathcal{B}}_{A}}\right)+\frac{x}{\frac{2}{n} \widehat{\mathcal{B}}_{A}}\left(\frac{\widehat{\mathcal{B}}_{B}}{\widehat{\mathcal{B}}_{A}}\right) \quad \text { for } \quad x \in\left[0, \frac{2}{n} \widehat{\mathcal{B}}_{A}\right] . \\
\forall j \in\{1, \ldots, n\} \quad F_{A, j}^{*}(x)=\frac{x}{\frac{2}{n} \widehat{\mathcal{B}}_{A}} \quad \text { for } \quad x \in\left[0, \frac{2}{n} \widehat{\mathcal{B}}_{A}\right] .
\end{gathered}
$$

Moreover, such a Nash equilibrium exists, and in any Nash equilibrium the expected payoff of the weak player $(B)$ is $n v\left(\widehat{\mathcal{B}}_{B} / 2 \widehat{\mathcal{B}}_{A}\right)-\widehat{\mathcal{B}}_{B}$ and the expected payoff of the strong player $(A)$ is $n v-n v\left(\widehat{\mathcal{B}}_{B} / 2 \widehat{\mathcal{B}}_{A}\right)-\widehat{\mathcal{B}}_{A}$.

The modified budgets delineate the three classes of equilibria in the non-constant-sum Colonel Blotto game. If $\widehat{\mathcal{B}}_{i}=\mathcal{B}_{i}$ for each $i=A, B$, then the players' resource constraints are so low, that in equilibrium both players expend all of their available resources. Conversely, if $\widehat{\mathcal{B}}_{i}=(n v / 2)$ for each $i=A, B$, then the players' resource constraints are so high, that in equilibrium neither player expends all of his available resources. Lastly, if $\widehat{\mathcal{B}}_{B}=\mathcal{B}_{B}$ and $\widehat{\mathcal{B}}_{A}=\left(n v \mathcal{B}_{B} / 2\right)^{1 / 2}$, then the weak player $(B)$ has a resource constraint that binds, but the strong player $(A)$ has a non-binding resource constraint.

In a similar manner, Friedman's Blotto-type game with the lottery CSF can also be 
extended to allow for budget-constrained linear costs with $c=1$. In this case, it is straightforward to show that a modified form of Theorem 2 applies in which each player's resource constraint $\mathcal{B}_{i}$ is replaced with his modified resource constraint defined as:

$$
\widehat{\mathcal{B}}_{B}=\min \left\{\mathcal{B}_{B}, \frac{\sum_{j=1}^{n} v_{j}}{4}\right\}
$$

for player B, and

$$
\widehat{\mathcal{B}}_{A}=\min \left\{\mathcal{B}_{A}, \frac{\sum_{j=1}^{n} v_{j}}{4},\left(\mathcal{B}_{B} \sum_{j=1}^{n} v_{j}\right)^{1 / 2}-\mathcal{B}_{B}\right\}
$$

for player A. As before, $\mathcal{B}_{A} \geq \mathcal{B}_{B}$ implies $\widehat{\mathcal{B}}_{A} \geq \widehat{\mathcal{B}}_{B}$.

Theorem 4. The pair of $n$-tuples $\mathbf{x}_{A}^{*}$ and $\mathbf{x}_{B}^{*}$ constitutes a Nash equilibrium of the Blottotype game with the lottery $C S F$, heterogenous battlefield valuations $\left\{v_{j}\right\}_{j=1}^{n}$, and budgetconstrained linear costs with $c=1$ and resource constraints $\mathcal{B}_{A}$ and $\mathcal{B}_{B}$, if

$$
\forall j \in\{1, \ldots, n\} \quad x_{A, j}^{*}=\left(\widehat{\mathcal{B}}_{A}\right) \frac{v_{j}}{\sum_{j^{\prime}=1}^{n} v_{j^{\prime}}} \quad \text { and } \quad x_{B, j}^{*}=\left(\widehat{\mathcal{B}}_{B}\right) \frac{v_{j}}{\sum_{j^{\prime}=1}^{n} v_{j^{\prime}}}
$$

The equilibrium expected payoffs are $\left(\widehat{\mathcal{B}}_{B} /\left(\widehat{\mathcal{B}}_{A}+\widehat{\mathcal{B}}_{B}\right)\right) \sum_{j=1}^{n} v_{j}-\widehat{\mathcal{B}}_{B}$ for the weak player $(B)$, and $\left(\widehat{\mathcal{B}}_{A} /\left(\widehat{\mathcal{B}}_{A}+\widehat{\mathcal{B}}_{B}\right)\right) \sum_{j=1}^{n} v_{j}-\widehat{\mathcal{B}}_{A}$ for the strong player $(A)$.

Again, the modified budgets delineate the three classes of equilibria that arise in the case that unused resources have positive value. As in the constant-sum formulations of the Colonel Blotto game and Friedman's Blotto-type game, the primary linkage across the individual component conflicts is through the implicit opportunity cost of resources. Thus, the nature of the incentives in the constant-sum games is, for the most part, robust to the relaxation of the use-it-or-lose-it cost feature.

\subsection{Infrastructure Costs}

The case of costs arising from infrastructure investment provides another example of a nonseparable cost function. Recall that by an infrastructure investment, we mean a nontargetable force technology that provides a uniform level of force across all battlefields. We also assume that an investment in infrastructure serves as a perfect substitute for the targetable force in each battlefield. This assumption allows us to treat the sum of player $i$ 's infrastructure investment and his targeted force to a given battlefield $j$ as a single choice variable $\widehat{x}_{i, j}$, 
which we call player $i$ 's effective force allocation to battlefield $j$. It is this allocation that enters into the contest success function for that battlefield.

Application of this type of nonseparable cost function originates with Lizzeri and Persico (2001), who examine two political parties engaged in redistributive competition with a continuum of voters, targetable taxes and transfers, and public good provision. ${ }^{8}$ We follow Lizzeri and Persico's focus on the case of a zero-one infrastructure technology that, when employed, provides a uniform level of force across all of the battlefields. However, our results may be directly extended to allow for a more general lumpy, or discrete, infrastructure technology.

Consider a game with the auction battlefield contest success function and a linear count objective function with homogeneous battlefields with common value $v$. For simplicity we focus on the asymmetric case in which, both players have linear costs with $c=1$, but only player B has the opportunity to invest in infrastructure. That is, in addition to the direct targeting of forces, player $\mathrm{B}$ has the opportunity to make a zero-one infrastructure investment (denoted by an indicator function $\iota_{I}$ ) at $\operatorname{cost} c_{I}$ which provides an effective force allocation of $I$ to each of the $n$ battlefields. We focus on the case in which the infrastructure investment is efficient, $c_{I}<n I$, and the value of each battlefield is larger than the per battlefield cost of the infrastructure investment, $v>\left(c_{I} / n\right)$. If player $\mathrm{B}$ utilizes the infrastructure technology $\left(\iota_{I}=1\right)$, then the total force that player B allocates to each battlefield $j$ is calculated as the sum of the targetable forces, $x_{B, j}$, and the infrastructure investment, $I$. Let $\widehat{\mathbf{x}}_{B} \equiv\left(x_{B, 1}+\iota_{I} I, x_{B, 2}+\iota_{I} I, \ldots, x_{B, n}+\iota_{I} I\right)$ denote player B's effective force allocation. ${ }^{9}$ When the two players allocate the same level of effective force, $x_{A, j}=\widehat{x}_{B, j}$, to a battlefield $j$, player B is assumed to win the battlefield.

It is clear that there is no pure-strategy equilibrium for this class of games. For player A, a mixed strategy is an $n$-variate distribution function which specifies player A's randomization in the allocation of targetable forces across the battlefields. Because (i) player B's effective force allocation is given by the $n$-tuple $\widehat{\mathbf{x}}_{B}=\left(x_{B, 1}+I \iota_{I}, \ldots, x_{B, n}+I \iota_{I}\right)$ and (ii) for any $n$-tuple of effective forces there exists a unique cost-minimizing combination of the targetable force and the infrastructure investment, it will be convenient to state player B's mixed strategy in terms of his $n$-tuple of effective forces.

\footnotetext{
${ }^{8}$ Because the model in Lizzeri and Persico (2001) assumes a continuum of voters, mixed strategies are unidimensional. A variation of this game with a finite set of voters and multidimensional mixed strategies is examined in Roberson (2008).

${ }^{9}$ Under these assumptions, the unit cost of infrastructure investment is $c_{u}=\left(c_{I} / I\right)$. This zero-one infrastructure investment corresponds to a simplified form of infrastructure costs in which the term min $\widehat{x}_{B, j}$ is replaced with $\iota_{I} \cdot I$, where $\iota_{I}$ takes a value of one if $\min _{j} \widehat{x}_{B, j} \geq I$.
} 
Theorem 5. Assume that $v>I>\left(c_{I} / n\right)$ and $c=1$. A Nash equilibrium of the game with asymmetric infrastructure investment is for each player to allocate his forces according to the following n-variate distribution functions. For player $A$ and $\mathbf{x} \in[0, v]^{n}$

$$
P_{A}^{*}(\mathbf{x})=\left(1-\frac{v-I+\left(c_{I} / n\right)}{v}\right)+\frac{\min _{j}\left\{\min \left\{x_{j}, c_{I} / n\right\}\right\}}{v}+\frac{\min _{j}\left\{\max \left\{x_{j}-I, 0\right\}\right\}}{v}
$$

Similarly for player B's effective force

$$
\widehat{P}_{B}^{*}(\widehat{\mathbf{x}})= \begin{cases}\frac{\min _{j}\left\{\min \left\{\widehat{x}_{j}, c_{I} / n\right\}\right\}}{v} & \text { if } \widehat{\mathbf{x}} \in\left\{[0, v]^{n}-[I, v]^{n}\right\} \\ \frac{\min _{j}\left\{\widehat{x}_{j}\right\}}{v} & \text { if } \widehat{\mathbf{x}} \in[I, v]^{n}\end{cases}
$$

Player $B$ chooses to make the infrastructure investment with probability $1-\frac{c_{I} / n}{v}$. The expected payoff for player $A$ is 0 , and the expected payoff for player $B$ is $n I-c_{I}$.

It is straightforward to demonstrate that this pair of strategies is indeed an equilibrium. Note also that one may verify that if an $n$-tuple of effective forces $\widehat{\mathbf{x}}_{B}$ is contained in the support of player B's mixed strategy $\left(\operatorname{Supp}\left(\widehat{P}_{B}\right)\right)$, then either $\iota_{i}=0$ and the $n$-tuple of targetable forces $\mathbf{x}_{B}$ is contained in the set $\left[0,\left(c_{I} / n\right)\right]^{n}$ or $\iota_{i}=1$ and the $n$-tuple of targetable forces $\mathbf{x}_{B}$ is contained in the set $\mathbf{x}_{B} \in[0, v-I]^{n}$. The linkage in player B's force allocations arises from the fact that it is suboptimal for player $\mathrm{B}$ to choose an $n$-tuple of targetable forces $\mathbf{x}_{B} \in\left[\left(c_{I} / n\right), I\right)^{n}$ and to not make the infrastructure investment, $\iota_{I}=0$, a strategy that has a corresponding cost of $\sum_{j=1}^{n} x_{B, j} \in\left[c_{I}, n I\right)$. By choosing to make only the infrastructure investment, $\iota_{I}=1$, at $\operatorname{cost} c_{I} \leq \sum_{j=1}^{n} x_{B, j}$, player B obtains a strictly higher level of effective force, $(I, \ldots, I)>\mathbf{x}_{B}$ for any $\mathbf{x}_{B} \in\left[\left(c_{I} / n\right), I\right)^{n}$. That is, by choosing the infrastructure investment, $\iota_{I}=1$ at cost $c_{I}$, over an $n$-tuple of targetable forces $\mathbf{x}_{B} \in\left[\left(c_{I} / n\right), I\right)^{n}$ (and no infrastructure investment, $\iota_{I}=0$ ) player B strictly increases his level of effective force, but does not increase his costs. Then, because in any equilibrium the support of player B's randomization over effective forces contains no $n$-tuples $\widehat{\mathbf{x}}_{B}$ in the set $\left[\left(c_{I} / n\right), I\right)^{n}$, it follows directly that for any equilibrium strategy $P_{A}$ for player A, the intersection of $\operatorname{Supp}\left(P_{A}\right)$ with $\left[\left(c_{I} / n\right), I\right)^{n}$ is also necessarily empty.

Intuitively, when player B stochastically employs the infrastructure investment, the fact that the investment provides an identical (positive) level of force to each battlefield means that there is automatically a linkage in the effective force allocations across battlefields. Moreover, this lumpy infrastructure choice also induces correlation in the allocation of the targetable forces across battlefields. Due to the construction of equilibrium mixed strategies, 
a similar type of correlation structure arises in player A's strategy, despite the fact that he does not have access to the infrastructure investment.

The intuition of this example also extends to the case of the budget-constrained use-it-orlose-it cost structure. As long as we maintain the assumption of an auction contest success function, the tradeoff between targetability and efficiency is captured in the endogenous correlation structure arising in the mixed-strategy equilibria. Under the lottery contest success function and a linear count objective, equilibrium does not in general require mixed strategies. As a consequence incorporating infrastructure investments does not lead to the same tradeoff between efficiency and targetability that arises with an auction contest success function. To our knowledge infrastructure investments have not yet been formally examined in this context, although, due to the non-monotonicity of the cost of providing different effective force levels, we expect a wealth of equilibrium behaviors to arise.

\section{Multiple Battlefields with Objective Linkages}

The objective function maximized in the standard formulation of the Colonel Blotto game is the linear pure-count objective. This is only one of many objectives that are relevant to applications of the model. Consider for example the nonlinear majoritarian objective in which the overall conflict is winner-take-all, and the winner is the player who wins a majority of battlefields (with $n$ - the number of battlefields - odd). Such structural linkages

may also be asymmetric across the set of players. For example, in the case of the attack and defense of a network of targets, the loss of a single target, or a particular configuration of targets, may be sufficient to disable the entire network. Thus, the attacker has a bestshot objective and seeks to destroy any one of the subsets of targets that would disable the network. Conversely, the defender has a weakest-link objective and seeks to prevent the network from being disabled.

\subsection{Majoritarian Objective}

The characterization of Nash equilibrium in the multi-battlefield conflict with a majoritarian objective and an auction battlefield contest success function is largely an open question. Only the case of three battlefields with symmetric battlefield values and costs has been addressed in the literature. We begin with the case of linear costs, and then examine the case of budget-constrained use-it-or-lose-it costs. 
Suppose that the benefit from winning a majority of battlefields is symmetric across players, $w_{A}=w_{b}=w=2$ in equation (3), and that players have symmetric linear costs with $c=1$. Szentes and Rosenthal (2003a) provide an equilibrium which is summarized in the following theorem.

Theorem 6 (Szentes and Rosenthal (2003a)). Let the tetrahedron $T$ be defined by the convex hull of the four points $(1,1,0),(1,0,1),(0,1,1)$, and $(0,0,0)$. A Nash equilibrium of the symmetric majoritarian objective game with $n=3, w=2$, linear costs with $c=1$, and the auction CSF is for each player to allocate his forces as follows. Each player draws 3tuples, $\left(x_{1}, x_{2}, x_{3}\right)$, from the uniform probability measure on the surface $S$ of $T$ and allocates resources according to $\left(\left(x_{1}\right)^{2},\left(x_{2}\right)^{2},\left(x_{3}\right)^{2}\right)$. The equilibrium expected payoff to each player is 0.

Although in Szentes and Rosenthal (2003a) each battlefield is modeled as a standard first-price (winner-pay) auction, one can appeal to Szentes's (2005) result on transforming an equilibrium strategy profile from one auction to another in order to solve for the case of sunk expenditure. Given the transformation from the equilibrium strategy profile in the first-price winner-pay auction to that in an all-pay auction, the proof of Theorem 6 follows along the line of argument for the first-price auction given in Szentes and Rosenthal (2003a). In the following discussion we provide only a brief sketch of the proof of Theorem 6 . Let $P^{*}$ denote the trivariate joint distribution function generated by the randomization described above, and let $F_{j, j^{\prime}}^{*}$ denote $P^{*}$ 's bivariate marginal distribution function for battlefields $j$ and $j^{\prime}$. For any allocation of resources $\left(\left(x_{1}\right)^{2},\left(x_{2}\right)^{2},\left(x_{3}\right)^{2}\right) \in \mathbb{R}_{+}^{3}$, the probability that player $i$ wins at least two battlefields, or equivalently a majority, is given by

$$
\begin{aligned}
\operatorname{Prob}( & \left.\sum_{j=1}^{3} I_{\left\{\left(x_{A, j}, x_{B, j}, \omega_{j}\right) \in \mathcal{W}_{A, j}\right\}} \geq 2 \mid\left(\left(x_{1}\right)^{2},\left(x_{2}\right)^{2},\left(x_{3}\right)^{2}\right), P^{*}\right)= \\
& F_{1,2}^{*}\left(\left(x_{1}\right)^{2},\left(x_{2}\right)^{2}\right)+F_{1,3}^{*}\left(\left(x_{1}\right)^{2},\left(x_{3}\right)^{2}\right)+F_{2,3}^{*}\left(\left(x_{2}\right)^{2},\left(x_{3}\right)^{2}\right)-2 P^{*}\left(\left(x_{1}\right)^{2},\left(x_{2}\right)^{2},\left(x_{3}\right)^{2}\right)
\end{aligned}
$$

where the last term corrects for the fact that the probability that player $i$ wins all three battlefields is counted three times, once in each of the three bivariate marginal distributions. As Szentes and Rosenthal (2003a) show, for any x on the surface $S$ of the tetrahedron $T$, the resource allocation $\left(\left(x_{1}\right)^{2},\left(x_{2}\right)^{2},\left(x_{3}\right)^{2}\right)$ is distributed according to

$$
P^{*}\left(\left(x_{1}\right)^{2},\left(x_{2}\right)^{2},\left(x_{3}\right)^{2}\right)=\frac{x_{1} x_{2}}{2}+\frac{x_{1} x_{2}}{2}+\frac{x_{1} x_{2}}{2}-\frac{\left(x_{1}\right)^{2}+\left(x_{2}\right)^{2}+\left(x_{3}\right)^{2}}{4}
$$


and for each $j, j^{\prime} \in\{1,2,3\}$ has the corresponding bivariate marginal distributions

$$
F_{j, j^{\prime}}^{*}\left(\left(x_{j}\right)^{2},\left(x_{j^{\prime}}\right)^{2}\right)=x_{j} x_{j^{\prime}}
$$

It then follows that for any $\left(x_{1}, x_{2}, x_{3}\right)$ on the surface $S$, player $i$ 's expected payoff from the resource allocation $\left(\left(x_{1}\right)^{2},\left(x_{2}\right)^{2},\left(x_{3}\right)^{2}\right)$ is

$$
\begin{aligned}
& U_{i}\left(\left(\left(x_{1}\right)^{2},\left(x_{2}\right)^{2},\left(x_{3}\right)^{2}\right), P^{*}\right)= \\
& 2 \cdot \operatorname{Prob}\left(\sum_{j=1}^{3} I_{\left\{\left(x_{A, j}, x_{B, j}, \omega_{j}\right) \in \mathcal{W}_{A, j}\right\}} \geq 2 \mid\left(\left(x_{1}\right)^{2},\left(x_{2}\right)^{2},\left(x_{3}\right)^{2}\right), P^{*}\right)-\sum_{j=1}^{3}\left(x_{j}\right)^{2}
\end{aligned}
$$

which is equal to zero. Ruling out profitable deviations to 3-tuples outside of the surface $S$ is more involved. For further details see Szentes and Rosenthal (2003a).

In the case of the symmetric Colonel Blotto majority game with $n=3$ (i.e., auction CSF, majoritarian objective, and budget-constrained use-it-or-lose-it costs with symmetric resource constraints $\mathcal{B}_{A}=\mathcal{B}_{B}=\mathcal{B}$ ), any solution to the pure count objective game is also a solution to the majoritarian objective game (see Borel and Ville 1938). To see this note that as a result of the symmetric resource constraint and the fact that each player uses all of his available resources, each player wins at least one battlefield. Formally, let $P_{i}$ be a mixed strategy in which $\operatorname{Supp}\left(P_{i}\right) \subseteq \overline{\mathcal{S}} \equiv\left\{\mathrm{x} \in \mathbb{R}_{+}^{3} \mid \sum_{j=1}^{3} x_{j}=\mathcal{B}\right\}$ and which does not place strictly positive mass on any $n$-tuple. If player $i$ is playing such a mixed strategy $P_{i}$, then for all budget-balancing $n$-tuples of resources $\mathbf{x}_{-i} \in \overline{\mathcal{S}}$ the probability that player $-i$ wins all three battlefields, $P_{i}\left(x_{-i, 1}, x_{-i, 2}, x_{-i, 3}\right)$, is equal to zero. ${ }^{10}$ Let $F_{i, j, j^{\prime}}$ denote $P_{i}$ 's bivariate marginal distribution function for battlefields $j$ and $j^{\prime}$. Because for all budget-balancing resource allocations no player wins all three battlefields (i.e., $P_{i}\left(x_{1}, x_{2}, x_{3}\right)=0$ for all $\mathbf{x} \in \overline{\mathcal{S}}$ ), it follows that if player $i$ uses the strategy $P_{i}$ with $\operatorname{Supp}\left(P_{i}\right) \subseteq \overline{\mathcal{S}}$ and player $-i$ uses any $n$-tuple $\mathbf{x} \in \overline{\mathcal{S}}$ then $^{11}$

$$
F_{i, 1}\left(x_{1}\right)+F_{i, 2}\left(x_{2}\right)+F_{i, 3}\left(x_{3}\right)-F_{i, 2,3}\left(x_{2}, x_{3}\right)-F_{i, 1,2}\left(x_{1}, x_{2}\right)-F_{i, 1,3}\left(x_{1}, x_{3}\right)=1 .
$$

\footnotetext{
${ }^{10}$ Intuitively, if $\operatorname{Supp}\left(P_{i}\right) \subset \overline{\mathcal{S}}$, then for all $\mathbf{x}_{-i} \in \overline{\mathcal{S}}$ the measure of the support of $P_{i}$ over the 3-box $\left[0, x_{-i, 1}\right] \times\left[0, x_{-i, 2}\right] \times\left[0, x_{-i, 3}\right]$ is necessarily zero. It is also clear that this does not apply if $\mathcal{B}_{A}>\mathcal{B}_{B}$.

${ }^{11}$ This expression is for the case that a tie occurs with probability zero. It is straightforward to incorporate a tie-breaking rule into this expression. However, it is clear that in any equilibrium ties occur with probability zero.
} 
Moreover, the probability that player $-i$ wins two battlefields, or a majority, is given by

$$
\operatorname{Prob}\left(\sum_{j=1}^{3} I_{\left\{\left(x_{A, j}, x_{B, j}, \omega_{j}\right) \in \mathcal{W}_{-i, j}\right\}} \geq 2 \mid \mathbf{x}, P_{i}\right)=F_{i, 2,3}\left(x_{2}, x_{3}\right)+F_{i, 1,2}\left(x_{1}, x_{2}\right)+F_{i, 1,3}\left(x_{1}, x_{3}\right) .
$$

Combining these two expressions, we see that

$$
\operatorname{Prob}\left(\sum_{j=1}^{3} I_{\left\{\left(x_{A, j}, x_{B, j}, \omega_{j}\right) \in \mathcal{W}_{-i, j}\right\}} \geq 2 \mid \mathbf{x}, P_{i}\right)=F_{i, 1}\left(x_{1}\right)+F_{i, 2}\left(x_{2}\right)+F_{i, 3}\left(x_{3}\right)-1 .
$$

Suppose player $i$ employs an equilibrium strategy $P_{i}^{*}$ with the corresponding unique set of equilibrium univariate marginal distributions given in Theorem 1 for the Colonel Blotto game with a linear pure-count objective. Then, player $-i$ 's expected payoff from the pure strategy $\mathbf{x}$ is

$U_{-i}\left(\mathbf{x}, P_{i}^{*}\right)=w \cdot \operatorname{Prob}\left(\sum_{j=1}^{3} I_{\left\{\left(x_{A, j}, x_{B, j}, \omega_{j}\right) \in \mathcal{W}_{-i, j}\right\}} \geq 2 \mid \mathbf{x}, P_{i}^{*}\right)=w \cdot\left[\frac{x_{1}}{\frac{2}{3} \mathcal{B}}+\frac{x_{2}}{\frac{2}{3} \mathcal{B}}+\frac{x_{3}}{\frac{2}{3} \mathcal{B}}-1\right] \leq \frac{w}{2}$

for all budget-balancing resource allocations $\mathbf{x}$. Because the game is constant sum and symmetric (with value $w$ ), it follows that this is also an equilibrium of the majority game.

The majoritarian game with the auction CSF and three battlefields has been extended in several directions. Laslier (2003) examines a variant of the symmetric Blotto majority game in which the three battlefields enter into the critical value count function with differing weights. Weinstein (2005) provides bounds on the equilibrium payoffs in the Blotto majority game with asymmetric budgets. Lastly, it should also be noted that it is straightforward to demonstrate that the relationship between the Colonel Blotto game and the non-constantsum formulation of the Colonel Blotto game (Kvasov 2007, Roberson and Kvassov 2008) may be extended to examine a non-constant-sum formulation of the symmetric Blotto majority game with budget-constrained linear costs. In particular in the case of three homogenous battlefields and symmetric budget-constrained linear costs with resource constraint $\mathcal{B} \leq$ $(w / 2)$ and $c=1$, any equilibrium of the symmetric Colonel Blotto pure-count objective game is an equilibrium of the symmetric Blotto majority game with budget-constrained linear costs.

Under the Tullock contest success function (see footnote 7), Snyder (1989) and Klumpp and Polborn (2006) examine a symmetric game with the majoritarian objective $\left(w_{A}=w_{B}=\right.$ 
$w)$ and linear costs $(c=1) .{ }^{12}$ Consider the special case of the lottery CSF and an odd number of battlefields. For any collection $C$ of battlefields, the probability that player $i$ wins each and every battlefield in the set $C$ and none of the battlefields outside $C$ is given by

$$
f_{i}(C)=\left[\prod_{j \in C} p_{i, j}\left(x_{i, j}, x_{-i, j}\right)\right]\left[\prod_{j \notin C}\left(1-p_{i, j}\left(x_{i, j}, x_{-i, j}\right)\right)\right] .
$$

The probability that player $i$ wins a majority of the battlefields is given by

$$
q_{i, m}\left(\mathbf{x}_{i}, \mathbf{x}_{-i}\right)=\sum_{S=\frac{n+1}{2}}^{n} \sum_{\{C \mid \# C=S\}} f_{i}(C)
$$

and player $i$ 's expected payoff is given by

$$
u_{i}\left(\mathbf{x}_{i}, \mathbf{x}_{-i}\right)=w q_{i, m}\left(\mathbf{x}_{i}, \mathbf{x}_{-i}\right)-\sum_{j=1}^{n} x_{i, j}
$$

Theorem 7 addresses the special case of the symmetric majoritarian game with the lottery CSF and linear costs. See Snyder (1989) and Klumpp and Polborn (2006) for the case of the Tullock CSF.

Theorem 7. Suppose the number of battlefields $n$ is odd. In the symmetric majoritarian game with $w_{A}=w_{B}=w$, linear costs with $c=1$, and the lottery CSF:

1. [Snyder(1989)] There exists a pure-strategy Nash equilibrium for $n \leq 5$. Any purestrategy Nash equilibrium $\left(\mathbf{x}_{A}^{*}, \mathbf{x}_{B}^{*}\right)$ satisfies

$$
\forall j \in\{1, \ldots, n\} \quad x_{A, j}^{*}=x_{B, j}^{*}=\frac{w}{4}\left[\frac{(n-1) !}{[((n-1) / 2) !]^{2}}\left(\frac{1}{2}\right)^{(n-1)}\right] .
$$

The equilibrium expected payoffs for each player are $\left(\frac{w}{2}\right)-\frac{n w}{4}\left[\frac{(n-1) !}{[((n-1) / 2) !]^{2}}\left(\frac{1}{2}\right)^{(n-1)}\right]$.

2. [Klumpp and Polborn (2006)] There exists no pure-strategy Nash equilibrium for $n \geq 7$. In any mixed strategy equilibrium players randomize over allocations that are uniform across battlefields (i.e. of the form $(x, x, \ldots, x)$ ) and earn expected payoffs equal to 0. A symmetric mixed strategy equilibrium exists.

As a point of reference, in the case of a single symmetric contest with common value $v$, linear costs with $c=1$, and the lottery CSF, each player $i$ 's equilibrium resource allocation

\footnotetext{
${ }^{12}$ Snyder (1989) examines a CSF in which the Tullock CSF is a special case.
} 
is $x_{i}=(v / 4)$. In any pure-strategy Nash equilibrium of the majoritarian objective game, part 1 of Theorem 7 shows that each player $i$ 's resource allocation to battlefield $j$ is equal to $(w / 4)$ times the probability that battlefield $j$ is pivotal, where the probability that battlefield $j$ is pivotal is equal to the probability that player $i$ wins exactly $(n-1) / 2$ of the other $n-1$ battlefields. In a symmetric equilibrium each player wins each battlefield with probability $(1 / 2)$, and thus, the probability that player $i$ wins exactly $(n-1) / 2$ of the other $n-1$ battlefields is given by ${ }^{13}$

$$
\left(\begin{array}{c}
n-1 \\
(n-1) / 2
\end{array}\right)\left(\frac{1}{2}\right)^{(n-1)}=\left[\frac{(n-1) !}{[((n-1) / 2) !]^{2}}\left(\frac{1}{2}\right)^{(n-1)}\right] .
$$

As Klumpp and Polborn (2006) show, for $n \geq 7$, the expected payoffs given in part 1 of Theorem 7 are strictly negative, and thus, there exists no pure-strategy Nash equilibrium over this parameter range. The intuition for this is that increasing the number of battlefields $n$ essentially reduces the level of noise in the overall contest because the randomization in the lottery CSF is independent across battlefields. As in a single contest with the Tullock CSF, pure-strategy equilibria fail to exist once the value of the CSF is sufficiently sensitive to the players' relative resource allocations. ${ }^{14}$ For $n \geq 7$, Klumpp and Polborn (2006) provide a symmetric mixed strategy equilibrium in which players randomize over allocations of the form $(x, x, \ldots, x)$ that are uniform across battlefields. These equilibria involve full rent dissipation.

The majoritarian objective is only one of many possible critical-value pure-count objectives. The case of a critical-value pure-count objective with the critical value $m=n-1$ (i.e., success requires winning all but one battlefield) and with a sufficient number of players (strictly greater than two) is examined by Szentes and Rosenthal (2003b), who characterize an equilibrium. For the case of three battlefields, a critical value of $m=2$ corresponds to the majoritarian objective, but with four or more battlefields the $m=n-1$ critical value is more closely related to the weakest-link objective in that success requires winning a super-majority of the battlefields.

\footnotetext{
${ }^{13}$ Using Stirling's formula for factorials, this pivot probability is approximately equal to $[\pi((n-1) / 2)]^{-1 / 2}$, which approaches zero as $n$ becomes arbitrarily large, but, as discussed in Chamberlain and Rothschild (1981), the rate of convergence is relatively slow.

${ }^{14}$ For a two-player symmetric contest with Tullock CSF and linear costs this arises when the exponent $r$ is geater than 2. See Baye et al. (1994) and Alcalde and Dahm (2010).
} 


\subsection{Weakest-Link and Best-Shot Objectives}

A line of research that examines games of attack and defense with multiple battlefields in which the players have asymmetric objective functions includes Gross (1950), Cooper and Restrepo (1967), Shubik and Weber (1981), Coughlin (1992), and Clark and Konrad (2007). ${ }^{15}$ For example, Clark and Konrad (2007) use the terms weakest-link objective and best-shot objective to describe the objectives of a defender and an attacker, respectively, who face each other in a network of battlefields in which successful defense requires that all targets within the network be successfully defended and successful attack requires only that at least one battlefield be won. ${ }^{16}$ The combination of the weakest-link and best-shot objectives accurately captures the attack and defense of a network consisting of numerous individual components but in which the failure or loss of a single component may be sufficient to disable the network. Such linkages arise in a number of infrastructure networks including electrical power grids, oil pipelines, transportation systems, communication systems, and cyber security.

Consider a game with $n$ battlefields, an attacker with the best-shot objective, a defender with the weakest-link objective, and linear costs with $c=1$. Let A denote the attacker who obtains a payoff of $w_{A}$ if he wins one or more battlefields, and $\mathrm{B}$ denote the defender who obtains a payoff of $w_{B}$ if he wins every battlefield. In the case that the players allocate the same level of resources to a battlefield, we assume that the defender wins the battlefield. We begin with the case in which in each battlefield the probability that player $i$ wins is determined by the auction CSF, and then examine the case of the lottery CSF.

Under the auction CSF it is clear that there is no pure strategy equilibrium for this class of games. As before a mixed strategy, or distribution of force, for player $i$ is an $n$-variate distribution function $P_{i}: \mathbb{R}_{+}^{n} \rightarrow[0,1]$. The proof of Theorem 8 is given in Kovenock and Roberson (2009). This theorem examines the game in which $w_{B} \geq n w_{A}$. The discussion following Theorem 8 also provides a summary of the equilibria in the remaining parameter

\footnotetext{
${ }^{15}$ Also related is the literature on terrorism and optimal defensive strategies (for a survey see Sandler and Enders (2004) or Kardes and Hall (2005)). Within this literature the focus is typically on attack and defense in the case that the attacker's objective is to successfully attack one target, rather than a subset of targets, and the defender's objective is to successfully defend all targets (see for example Bier, Oliverios, and Samuelson (2007) and Powell (2007a, b)). However, that literature differs from the formulation examined in this article in that the attacker's strategy space is restricted to choosing which single target to attack (or mixed strategies that are a probability distributions across targets). In contrast, the contest structure examined in this article allows the attacker to endogenously choose how many targets to attack, the correlation of attacks, and the level of force used in each attack.

${ }^{16}$ See also Hirshleifer (1983) who coins the terms "best-shot" and "weakest-link" in the context of voluntary provision of public goods.
} 
configurations.

Theorem 8 (Kovenock and Roberson (2009)). Consider an n-battlefield game of attack and defense in which player $A$ has a best-shot objective and valuation $w_{A}$, player $B$ has a weakestlink objective and valuation $w_{B}$, both players have linear costs with $c=1$, and battlefield outcomes are determined by the auction CSF. If $w_{B} \geq n w_{A}$, then a Nash equilibrium of the game is for each player to allocate his forces according to the following n-variate distribution functions: For player $A$ and $\mathbf{x} \in\left[0, w_{A}\right]^{n}$

$$
P_{A}^{*}(\mathbf{x})=\left(1-\frac{n w_{A}}{w_{B}}\right)+\left(\frac{x_{1}+x_{2}+\ldots+x_{n}}{w_{B}}\right)
$$

and for player $B$ and $\mathbf{x} \in\left[0, w_{A}\right]^{n}$

$$
P_{B}^{*}(\mathbf{x})=\frac{\min \left\{x_{1}+x_{2}+\ldots+x_{n}\right\}}{w_{A}}
$$

The expected payoff for player $A$ is 0 , and the expected payoff for player $B$ is $w_{B}-n w_{A}$.

It is useful to provide some intuition for Theorem 8. Recall that in a weakest-link network of $n$-targets the attacker need only win one target within the network in order to win the network and receives no additional benefit from winning more than one target. In the equilibrium characterized in Theorem 8 , for any realization of his random allocation $\mathbf{x}_{A}$, the attacker optimally allocates a strictly positive level of force to at most one target within the network. Given the defender's equilibrium distribution of force, the attacker receives a lower expected payoff from attacking more than one target. Although in equilibrium the attacker randomizes choosing each target with equal probability, the attacker's allocation of force to the target chosen varies stochastically in magnitude. Kovenock and Roberson (2009) show that this single attack property in which the attacker allocates a strictly positive level of force to at most one target applies to all Nash equilibria of the game in Theorem 8. They also extend the analysis to all other parameter configurations and to the case in which the game of attack and defense is over a weakest-link supra-network of best-shot and weakest-link networks.

The version of this game with lottery CSFs is analyzed by Clark and Konrad (2007) and for $w_{B}>(n-1) w_{A}$, equilibrium is characterized by Theorem 9 below. See Clark and Konrad (2007) for the remaining case that $w_{B} \leq(n-1) w_{A}$.

Theorem 9 (Clark and Konrad (2007)). Consider an n-battlefield game of attack and defense in which player $A$ has a best-shot objective and valuation $w_{A}$, player $B$ has a weakest-link 
objective and valuation $w_{B}$, both players have linear costs with $c=1$, and battlefield outcomes are determined by the lottery CSF. If $w_{B} \geq(n-1) w_{A}$, then the $n$-tuples $\mathbf{x}_{A}^{*}$ and $\mathbf{x}_{B}^{*}$ constitute a Nash equilibrium of the game if

$$
\forall j \in\{1, \ldots, n\} \quad x_{A, j}^{*}=\frac{\left(w_{A}\right)^{2}\left(w_{B}\right)^{n}}{\left(w_{A}+w_{B}\right)^{n+1}} \quad \text { and } \quad x_{B, j}^{*}=\frac{\left(w_{A}\right)\left(w_{B}\right)^{n+1}}{\left(w_{A}+w_{B}\right)^{n+1}}
$$

Both players have strictly positive expected payoffs in equilibrium.

The primary difference in the equilibrium behaviors described in Theorems 8 and 9 is that under the auction CSF the attacker, by attacking at most one target, randomizing over the identity of the target attacked, and randomizing over the size of the force used in the attack, optimally chooses to use a type of "stochastic guerilla warfare" strategy. The defender, although choosing to cover every target with a common, positive force level, also randomizes over the size of the force allocated. In contrast, under the lottery CSF, the noise in the outcome conditional on allocations is sufficient to eliminate the need to randomize over allocations. Even though a successful attack requires only that a single target in the weakest-link network be disabled, the attacker employs a pure strategy that allocates a strictly positive common level of force to every target. The defender responds in kind.

\subsection{Multiple Inputs}

In modeling multiple battlefields we have assumed that the outcome in each component contest $j$ is determined solely by the one-dimensional resource allocated by each player to that contest and a contest-specific random variable $\widetilde{\omega}_{j} .{ }^{17}$ There are also many instances in which the outcome in a component contest is determined by the interaction of multiple inputs. Golman and Page (2009) examine a game with budget-constrained use-it-or-lose-it costs and an augmented linear pure-count objective that sums the $n$ battlefield outcomes and the outcomes of additional contests formed by taking subsets of the $n$ battlefields and setting each player's allocation equal to the product of his allocations to battlefields in the subset. For example, consider a variant of the linear pure-count objective that has been augmented to allow for $\left(\begin{array}{l}n \\ 2\end{array}\right)$ additional contests formed by taking all pairs of battlefields. In each of the additional contests, denoted by $j, k$, the outcome is determined by the auction contest success function applied to the allocations $x_{A, j} \cdot x_{A, k}$ and $x_{B, j} \cdot x_{B, k}$. The outcome

\footnotetext{
${ }^{17}$ The one exception is the case of infrastructure costs, in which two perfectly substitutable inputs are collapsed into a one-dimensional allocation.
} 
function then takes the form,

$$
V_{A}\left(\mathbf{x}_{A}, \mathbf{x}_{B}\right)=\sum_{j=1}^{n} p_{A, j}\left(x_{A, j}, x_{B, j}\right)+\sum_{j=1}^{n-1} \sum_{k>j}^{n} p_{A, j, k}\left(x_{A, j} \cdot x_{A, k}, x_{B, j} \cdot x_{B, k}\right),
$$

where $p_{A, j}\left(x_{A, j}, x_{B, j}\right)$ denotes the auction contest success function in component contest $j$. This variation of the multiple battlefield model results in a constant-sum game with valuation $n+\left(\begin{array}{l}n \\ 2\end{array}\right)$. Golman and Page (2009) show that although there is no pure-strategy Nash equilibrium in this variation of the game with the $\left(\begin{array}{l}n \\ 2\end{array}\right)$ additional contests, there does exist a pure-strategy Nash equilibrium to the corresponding game in which there is one contest for each of the possible nonempty subsets of the $n$ allocations.

Also related is Arbatskaya and Mialon (2010) who examine a single contest with linear costs in which a Cobb-Douglas production function is used to map multiple inputs (or "activities") into an aggregate effort variable that is, in turn, entered into the lottery contest success function. Inputs may enter the production function asymmetrically and unit costs may differ across both inputs and players. In the model, placing a common, binding cap on each player's use of a given input tends to decrease the discriminatory power of the contest, thereby softening competition. At the same time, the cap may alter the relative strengths of the players. Because symmetry between players tends to increase competition, this may have an offsetting effect. As a consequence, unless the cap makes the conflict more symmetric, it tends to reduce rent dissipation.

\section{Conclusion}

Despite the significant progress since Borel's (1921) foundational model, the study of multibattlefield conflict remains an area with important open theoretical problems and potentially large returns to new conceptual formulations, practical application, and empirical testing. Space constraints have prevented us from examining many important extensions of the basic models described in this chapter. We briefly discuss a few of these here.

First, it is obvious that other contest success functions may be applied within battlefields such as the Tullock contest success functions with exponent greater than two, ${ }^{18}$ Lazear and Rosen's (1981) difference-form contest success functions, ${ }^{19}$ Konrad's (2002) treatment of

\footnotetext{
${ }^{18}$ In the case of a single contest, partial characterizations of equilibrium for this model for discrete approximations to a continuous strategy space have been derived by Baye et al. (1994) and Alcalde and Dahm (2010).

${ }^{19}$ Previous analyses of the Lazear-Rosen (1981) difference-form contest success function for single contests
} 
affine handicapping in the context of the auction CSF, or Skaperdas and Syropoulos's (1998) treatment of weighted asymmetric lottery CSFs. These last two contest success functions may be particularly useful in the analysis of conflicts in which each rival is advantaged in subsets of the battlefields (perhaps due to geography or pre-conflict investment in defensive position).

Moreover, although the existing literature has led us to frame the general problem of conflict with multiple battlefields as one with sunk costs of contesting and fixed prizes for winning each battlefield, other formulations of the contest within each battlefield are useful. One important case is that of count objectives in which individual battlefield values are dependent on the forces of the two players expended in the battlefield. For instance the game with a linear count objective, auction contest success function, and budget-constrained linear costs can be altered so that the victor in each each battlefield has a portion of his own expenditure above that of his rival reimbursed. When the portion of the victor's expenditure above that of his rival is completely reimbursed, the contest within each battlefield resembles a war of attrition with a constraint across battlefields on the sum of own bids. ${ }^{20}$

Previous work on multi-battlefield conflicts has focused almost exclusively on two-player games. The characterization of equilibrium for $n>2$ players engaged in conflict is of great interest. A wide array of issues arise $n$-player extensions that are either absent or unimportant in two-player games, including the exogenous or endogenous segmentation of conflict as well as the possibility that identity-dependent externalities may exist with respect to the overall contest winners or the winners of individual battlefields.

Friedman (1958) examines an $n$-player extension of the model described in Theorem 2, which employs a lottery contest success function, a linear count objective with heterogeneous battlefield valutions that are symmetric across players, and asymmetric budget constrained use-it-or-lose-it costs. He finds that each player allocates the same fraction of their respective budgets to a given battlefield and this fraction is the ratio of the battlefield value to the sum of

generally assume sufficient noise in the outcome and/or concavity of utility or convexity of cost to insure a pure strategy equilibrium. However, pure strategy equilibria do not generally exist for all specifications of noise and costs and the characterization of equilibrium in these models is incomplete. See for example Che and Gale (2000), who provide a partial characterization of the set of mixed strategy Nash equilibria with a specific type of exogenous noise. Dixit and Londregan $(1995,1996)$ employ the Lazear-Rosen CSF to model political competition across multiple battlefields. Their model may be interpreted as multi-battle conflict with a linear count objective and budget-constrained use-it-or-lose-it costs. See also Lindbeck and Weibull (1987) and Cox and McCubbins (1986).

${ }^{20}$ Standard (single battle) contests with rank-order externalites from rival bids have been analyzed by Baye et al. (2010) for the auction contest success fucntion and Chowdhury and Sheremeta (2010) for the lottery contest success function. 
battlefield values. An initial approach to the analysis of $n$-player multi-battlefield conflicts with an auction contest success function is Kovenock and Roberson's (2008b) analysis of the symmetric $n$ player Colonel Blotto game with a linear pure-count objective. In this extension, not only do equilibria exist in which each player competes in every battlefield, but segmented equilibria exist in which disjoint subsets of players in a partition of the set of $n_{p}$ players are matched with disjoint subsets of battlefields in a partition of the $n_{b}$ battlefields. In these segmented equilibria, each subset of players competes only for those battlefields in the matched subset of battlefields. Kovenock and Roberson also show that a type of segmented equilibrium exists with asymmetric budgets.

Multi-battlefield conflicts with incomplete information also remain relatively neglected. Natural candidates for parameters that are private information are parameters of the players' objective functions such as battlefield valuations or parameters of cost, such as budget constraints or unit cost of expenditures. To our knowledge, little work has been published to date in this area. Exceptions are Matros (2008) and Adamo and Matros (2009) who examine, under the lottery and auction CSFs respectively, games with a linear count objective that is symmetric across players and budget-constrained use-it-or-lose-it costs, where the players' budgets are private information.

All of the models examined in this chapter have involved a single stage with simultaneous moves. The introduction of dynamics into the analysis can take several forms. First, the assumption that the battlefields are contested simultaneously can be relaxed. Models in which battlefields are contested sequentially include Harris and Vickers (1987), Klumpp and Polborn (2006) and Agastya and McAfee (2006), Konrad and Kovenock (2005, 2009) and Sela (2008). The assumption that the contest within a given battlefield involves a simultaneous one-shot expenditure can also be relaxed. Alternating move models of sunk expenditure within a single contest environment in the spirit of the Shubik "Dollar Auction Game" (see O’Neill (1986) and Leininger $(1989,1991)$ ) have been extended to cover multiple battlefield conflicts (in the context of vote buying) by Dekel et al. (2008, 2009). ${ }^{21}$ Finally, the fact that the main results of this chapter provide equilibrium payoffs in terms of exogenous parameters such as resource budgets, number of battlefields, values of battlefields, unit costs of expenditures, and network structures, facilitates the use of these models as the final stage of multistage games in which these values are determined endogenously. This opens up a conflict theoretic framework with which to generate equilibrium models of the endogenous determination of the configuration of battlefields (including endogenous network

\footnotetext{
${ }^{21}$ See Konrad's chapter in this volume for more on dynamic conflicts.
} 
structures and network redundancies), ${ }^{22}$ resources constraints and cost structures, ${ }^{23}$ and coalition formation. ${ }^{24}$

In concluding, we note that the process of empirically testing the equilibrium predictions of the models described in this chapter has already begun. Several variants of the Colonel Blotto game described in section 3 have been examined experimentally by Avrahami and Kareev (2009), Arad and Rubinstein (2009), and Chowdhury, Kovenock and Sheremeta (2009). The game of attack and defense with weakest link and best-shot objectives in section 4.2 has been examined by Kovenock, Roberson and Sheremeta (2009). Clearly, at this time, this remains a relatively untouched area of research.

\section{References}

[1] Adamo, T., \& Matros, A. (2009). A Blotto game with incomplete information. Economics Letters, 105, 100-102.

[2] Agastya, M., \& McAfee, R.P. (2006). Continuing wars of attrition. unpublished manuscript.

[3] Alcalde, J., \& Dahm, M. (2010). Rent seeking and rent dissipation: a neutrality result. Journal of Public Economics, 94, 1-7.

[4] Arad, A., \& Rubinstein, A. (2009). Colonel Blotto's top secret files. Tel Aviv University and University of Tel Aviv Cafes, unpublished manuscript.

[5] Arbatskaya, M., \& Mialon, H.M. (2010). Multi-activity contests. Economic Theory, 43, 23-43.

\footnotetext{
${ }^{22}$ Goyal and Vigler (2010) examine the design of robust networks in a conflict in which players are budget constrained, the defender chooses the network design and his allocation of forces across battelfields prior to the attacker's allocation of forces, and a modified lottery CSF is employed. Kovenock, Mauboussin, and Roberson (2010) examine a two stage game in which either payer may pay to increase the number of battlefields in the first stage and players play a Colonel Blotto game with an auction CSF in the second stage. Wiser (2010) examines a simple contest theoretic version of the game Hex in which players simultanoeusly allocate resources across cells with linear costs and cell winners are determined by independent lottery CSFs.

${ }^{23}$ For example, the classical Colonel Blotto game generates payoffs that are functions of the respective player budgets and the value and number of battlefields. Viewing the respective budgets as one-dimensional resource allocations, the game can be embedded in a mutlistage game in which the budgets are determined endogenously.

${ }^{24}$ See, for instance, Kovenock and Roberson (2008a).
} 
[6] Avrahami, J., \& Kareev, Y. (2009). Do the weak stand a chance? Distribution of resources in a competitive environment. Cognitive Science, 33, 940-950.

[7] Baye, M.R., Kovenock, D., \& de Vries, C.G. (1994). The solution to the Tullock rentseeking game when $R>2$ : mixed-strategy equilibria and mean dissipation rates. Public Choice, 81, 363-380.

[8] Baye, M.R., Kovenock, D., \& de Vries, C.G. (2010). Contests with rank-order spillovers. Economic Theory, forthcoming.

[9] Bellman, R. (1969). On Colonel Blotto and analogous games. Siam Review, 11, 66-68.

[10] Bier, V. M., Oliveros, S., \& Samuelson, L. (2007). Choosing what to protect: strategic defensive allocation against an unknown attacker. Journal of Public Economic Theory, $9,563-587$.

[11] Blackett, D.W. (1954). Some Blotto games. Naval Research Logistics Quarterly, 1, 55-60.

[12] Blackett, D.W. (1958). Pure strategy solutions to Blotto games. Naval Research Logistics Quarterly, 5, 107-109.

[13] Borel, E. (1921). La theorie du jeu les equations integrales a noyau symetrique. Comptes Rendus del Academie, 173, 1304-1308; English translation by Savage, L. (1953). The theory of play and integral equations with skew symmetric kernels. Econometrica, 21, 97-100.

[14] Borel, E., \& Ville, J. (1938). Application de la théorie des probabilitiés aux jeux de hasard, Gauthier-Villars; reprinted in Borel, E., \& Chéron, A. (1991). Théorie mathematique du bridge à la portée de tous, Editions Jacques Gabay.

[15] Chamberlain, G., \& Rothschild, M. (1981). A note on the probability of casting a decisive vote. Journal of Economic Theory, 25, 152-162.

[16] Che, Y-K., \& Gale, I. (2000). Difference-form contests and the robustness of all-pay auctions. Games and Economic Behavior 30, 22-43.

[17] Chowdhury, S.M., Kovenock, D., \& Sheremeta, R. (2009). An experimental investigation of Colonel Blotto games, CESifo Working Paper No. 2688. 
[18] Chowdhury, S.M.,\& Sheremeta, R. (2010). A generalized Tullock contest. Public Choice, forthcoming.

[19] Clark, D.J., \& Konrad, K.A. (2007). Asymmetric conflict: weakest link against best shot. Journal of Conflict Resolution, 51, 457-469.

[20] Cooper, J. N., \& Restrepo, R.A. (1967). Some problems of attack and defense. Siam Review, 9, 680-691.

[21] Coughlin, P.J. (1992). Pure strategy equilibria in a class of systems defense games. International Journal of Game Theory, 20, 195-210.

[22] Cox, G.W., \& McCubbins, M.D. (1986). Electoral politics as redistributive game. Journal of Politics, 48, 370-389.

[23] Dekel, E., Jackson, M.O., \& Wolinsky, A. (2008). Vote buying: general elections. Journal of Political Economy, 116, 351-380.

[24] Dekel, E., Jackson, M.O., \& Wolinsky, A. (2009). Vote buying: legislatures and lobbying. Quarterly Journal of Political Science, 4, 103-128.

[25] Dixit, A., \& Londregan, J. (1995). Redistributive politics and economic efficiency. American Political Science Review, 89, 856-866.

[26] Dixit, A., \& Londregan, J. (1996). The determinants of success of special interests in redistributive politics. Journal of Politics, 58, 1132-1155.

[27] Friedman, L. (1958). Game-theory models in the allocation of advertising expenditures. Operations Research, 6, 699-709.

[28] Golman, R., \& Page, S.E. (2009). General Blotto: games of strategic allocative mismatch. Public Choice, 138, 279-299.

[29] Goyal, S., \& Vigler, A. (2010). Robust networks. University of Cambridge, unpublished manuscript.

[30] Gross, O. (1950). Targets of differing vulnerability with attack stronger than defense. RM-359, RAND Corporation, Santa Monica.

[31] Gross, O., \& Wagner, R. (1950). A continuous Colonel Blotto game. RM-408, RAND Corporation, Santa Monica. 
[32] Harris, C., \& Vickers, J. (1987). Racing with uncertainty. Review of Economic Studies, $54,1-21$.

[33] Hart, S. (2008). Discrete Colonel Blotto and General Lotto games. International Journal of Game Theory, 36, 441-460.

[34] Hirshleifer, J. (1983). From weakest-link to best-shot: the voluntary provision of public goods. Public Choice, 41, 371-386.

[35] Kardes, E., \& Hall, R. (2005). Survey of literature on strategic decision-making in the presence of adversaries. CREATE Report, University of Southern California.

[36] Klumpp, T., \& Polborn, M.K. (2006). Primaries and the New Hampshire effect. Journal of Public Economics, 90, 1073-1114.

[37] Konrad, K.A. (2002). Investment in the absence of property rights. European Economic Review, 46, 1521-1537.

[38] Konrad, K.A., \& Kovenock, D. (2005). Equilibrium and efficiency in the tug-of-war. CEPR Discussion Paper No. 5205.

[39] Konrad, K.A., \& Kovenock, D. (2009). Multi-battle contests. Games and Economic Behavior, 66, 256-274.

[40] Kovenock, D., \& Roberson, B. (2008a). Coalitional Colonel Blotto games with application to the economics of alliances. WZB working paper SP II 2008-02.

[41] Kovenock, D., \& Roberson, B. (2008b).The n-player Colonel Blotto game. Purdue University, unpublished manuscript.

[42] Kovenock, D., \& Roberson, B. (2009). The Optimal defense of networks of targets. Purdue University, unpublished manuscript.

[43] Kovenock, D., Roberson, B., \& Sheremeta, R. (2009). The attack and defense of weakestlink networks. Chapman University, unpublished manuscript.

[44] Kovenock, D., Mauboussin, M., \& Roberson, B. (2010). Picking (the number of) your battles: Colonel Blotto with an endogenous number of battlefields. Purdue University, unpublished manuscript. 
[45] Kvasov, D. (2007). Contests with limited resources. Journal of Economic Theory, 127, 738-748.

[46] Laslier, J.F. (2002). How two-party competition treats minorities. Review of Economic Design, 7, 297-307.

[47] Laslier, J.F. (2003). Party objectives in the "divide a dollar" electoral competition. in Austen-Smith, D., \& Duggan, J., eds. Social Choice and Strategic Decisions: Essays in Honor of Jeffrey S. Banks, Springer, Berlin.

[48] Laslier, J.F., \& Picard, N. (2002). Distributive politics and electoral competition. Journal of Economic Theory, 103, 106-130.

[49] Lazear, E.P., \& Rosen, S. (1981). Rank-order tournaments as optimum labor contracts. Journal of Political Economy, 89, 841-864.

[50] Leininger, W. (1989). Escalation and cooperation in conflict situations-the dollar auction revisited. Journal of Conflict Resolution, 33, 231-254.

[51] Leininger, W. (1991). Patent competition, rent dissipation, and the persistence of monopoly: the role of research budgets. Journal of Economic Theory, 53, 146-172.

[52] Lindbeck, A., \& Weibull, J. (1987). Balanced-budget redistribution as the outcome of political competition. Public Choice, 52, 272-297.

[53] Lizzeri, A., \& Persico, N. (2001). The provision of public goods under alternative electoral incentives. American Economic Review, 91, 225-239.

[54] Macdonell, S., \& Mastronardi, N. (2010). Colonel Blotto equilibria: a complete characterization in the two battlefield case. University of Texas, unpublished manuscript.

[55] Matros, A. (2008). Chinese auctions. University of Pittsburgh, unpublished manuscript.

[56] O'Neill, B. (1986). International escalation and the dollar auction. Journal of Conflict Resolution, 30, 33-50.

[57] Powell, R. (2007a). Defending against terrorist attacks with limited resources. American Political Science Review, 101, 527-541.

[58] Powell, R. (2007b). Allocating defensive resources with private information about vulnerability. American Political Science Review, 101, 799-809. 
[59] Roberson, B., \& Kvasov, D. (2008). The non-constant-sum Colonel Blotto game. CESifo Working Paper No. 2378.

[60] Roberson, B. (2006). The Colonel Blotto game. Economic Theory, 29, 1-24.

[61] Roberson, B. (2008). Pork-barrel politics, targetable policies, and fiscal federalism. Journal of the European Economic Association, 6, 819-844.

[62] Robson, A.R.W. (2005). Multi-item contests. Australian National University, Working Paper No. 446.

[63] Sandler, T., \& Enders, W. (2004). An Economic perspective on transnational terrorism. European Journal of Political Economy, 20, 301-316.

[64] Sela, A. (2008). Sequential two-prize contests. CEPR Discussion Paper No. 6769.

[65] Shubik, M., \& Weber, R.J. (1981). Systems defense games: Colonel Blotto, command and control. Naval Research Logistics Quarterly, 28, 281-287.

[66] Skaperdas, S., \& Syropoulos, C. (1998). Complementarity in contests. European Journal of Political Economy, 14, 667-684.

[67] Snyder, J. (1989). Election goals and the allocation of campaign resources. Econometrica, 57, 637-660.

[68] Szentes, B. (2005). Equilibrium transformations and the revenue equivalence theorem. Journal of Economic Theory, 120, 175-205.

[69] Szentes, B., \& Rosenthal, R.W. (2003a). Three-object two-bidder simultaneous auctions: chopsticks and tetrahedra. Games and Economic Behavior, 44, 114-133.

[70] Szentes, B., \& Rosenthal, R.W. (2003b). Beyond chopsticks: symmetric equilibria in majority auction games. Games and Economic Behavior, 45, 278-295.

[71] Tukey, J.W. (1949). A problem of strategy. Econometrica, 17, 73.

[72] Weinstein, J. (2005). Two notes on the Blotto game. Northwestern University, unpublished manuscript.

[73] Wiser, M. (2010). Optimal effort in a simultaneous move game of Hex. Louisiana State University, Dept. of Economics, unpublished manuscript. 


\section{CESifo Working Paper Series}

for full list see www.cesifo-group.org/wp

(address: Poschingerstr. 5, 81679 Munich, Germany, office@cesifo.de)

3103 Andrea F. Presbitero and Alberto Zazzaro, Competition and Relationship Lending: Friends or Foes?, June 2010

3104 Dan Anderberg and Yu Zhu, The Effect of Education on Martial Status and Partner Characteristics: Evidence from the UK, June 2010

3105 Hendrik Jürges, Eberhard Kruk and Steffen Reinhold, The Effect of Compulsory Schooling on Health - Evidence from Biomarkers, June 2010

3106 Alessandro Gambini and Alberto Zazzaro, Long-Lasting Bank Relationships and Growth of Firms, June 2010

3107 Jenny E. Ligthart and Gerard C. van der Meijden, Coordinated Tax-Tariff Reforms, Informality, and Welfare Distribution, June 2010

3108 Vilen Lipatov and Alfons Weichenrieder, Optimal Income Taxation with Tax Competition, June 2010

3109 Malte Mosel, Competition, Imitation, and R\&D Productivity in a Growth Model with Sector-Specific Patent Protection, June 2010

3110 Balázs Égert, Catching-up and Inflation in Europe: Balassa-Samuelson, Engel's Law and other Culprits, June 2010

3111 Johannes Metzler and Ludger Woessmann, The Impact of Teacher Subject Knowledge on Student Achievement: Evidence from Within-Teacher Within-Student Variation, June 2010

3112 Leif Danziger, Uniform and Nonuniform Staggering of Wage Contracts, July 2010

3113 Wolfgang Buchholz and Wolfgang Peters, Equity as a Prerequisite for Stable Cooperation in a Public-Good Economy - The Core Revisited, July 2010

3114 Panu Poutvaara and Olli Ropponen, School Shootings and Student Performance, July 2010

3115 John Beirne, Guglielmo Maria Caporale and Nicola Spagnolo, Liquidity Risk, Credit Risk and the Overnight Interest Rate Spread: A Stochastic Volatility Modelling Approach, July 2010

3116 M. Hashem Pesaran, Predictability of Asset Returns and the Efficient Market Hypothesis, July 2010

3117 Dorothee Crayen, Christa Hainz and Christiane Ströh de Martínez, Remittances, Banking Status and the Usage of Insurance Schemes, July 2010 
3118 Eric O’N. Fisher, Heckscher-Ohlin Theory when Countries have Different Technologies, July 2010

3119 Huw Dixon and Hervé Le Bihan, Generalized Taylor and Generalized Calvo Price and Wage-Setting: Micro Evidence with Macro Implications, July 2010

3120 Laszlo Goerke and Markus Pannenberg, 'Take it or Go to Court' - The Impact of Sec. 1a of the German Protection against Dismissal Act on Severance Payments -, July 2010

3121 Robert S. Chirinko and Daniel J. Wilson, Can Lower Tax Rates be Bought? Business Rent-Seeking and Tax Competition among U.S. States, July 2010

3122 Douglas Gollin and Christian Zimmermann, Global Climate Change and the Resurgence of Tropical Disease: An Economic Approach, July 2010

3123 Francesco Daveri and Maria Laura Parisi, Experience, Innovation and Productivity Empirical Evidence from Italy's Slowdown, July 2010

3124 Carlo V. Fiorio and Massimo Florio, A Fair Price for Energy? Ownership versus Market Opening in the EU15, July 2010

3125 Frederick van der Ploeg, Natural Resources: Curse or Blessing?, July 2010

3126 Kaisa Kotakorpi and Panu Poutvaara, Pay for Politicians and Candidate Selection: An Empirical Analysis, July 2010

3127 Jun-ichi Itaya, Makoto Okamura and Chikara Yamaguchi, Partial Tax Coordination in a Repeated Game Setting, July 2010

3128 Volker Meier and Helmut Rainer, On the Optimality of Joint Taxation for NonCooperative Couples, July 2010

3129 Ryan Oprea, Keith Henwood and Daniel Friedman, Separating the Hawks from the Doves: Evidence from Continuous Time Laboratory Games, July 2010

3130 Mari Rege and Ingeborg F. Solli, The Impact of Paternity Leave on Long-term Father Involvement, July 2010

3131 Olaf Posch, Risk Premia in General Equilibrium, July 2010

3132 John Komlos and Marek Brabec, The Trend of BMI Values by Centiles of US Adults, Birth Cohorts 1882-1986, July 2010

3133 Emin Karagözoğlu and Arno Riedl, Information, Uncertainty, and Subjective Entitlements in Bargaining, July 2010

3134 John Boyd, Gianni De Nicolò and Elena Loukoianova, Banking Crises and Crisis Dating: Theory and Evidence, July 2010 
3135 Michael R. Baye, Dan Kovenock and Casper G. de Vries, The Herodotus Paradox, July 2010

3136 Martin Kolmar and Hendrik Rommeswinkel, Group Contests with Complementarities in Efforts, July 2010

3137 Carolina Manzano and Xavier Vives, Public and Private Learning from Prices, Strategic Substitutability and Complementarity, and Equilibrium Multiplicity, July 2010

3138 Axel Löffler, Gunther Schnabl and Franziska Schobert, Inflation Targeting by Debtor Central Banks in Emerging Market Economies, July 2010

3139 Yu-Fu Chen and Michael Funke, Global Warming and Extreme Events: Rethinking the Timing and Intensity of Environmental Policy, July 2010

3140 Lawrence M. Kahn, Labor Market Policy: A Comparative View on the Costs and Benefits of Labor Market Flexibility, July 2010

3141 Ben J. Heijdra, Jochen O. Mierau and Laurie S.M. Reijnders, The Tragedy of Annuitization, July 2010

3142 Erkki Koskela, Outsourcing Cost and Tax Progression under Nash Wage Bargaining with Flexible Outsourcing, July 2010

3143 Daniel Osberghaus and Christiane Reif, Total Costs and Budgetary Effects of Adaptation to Climate Change: An Assessment for the European Union, August 2010

3144 Philip E. Graves, Benefit-Cost Analysis of Environmental Projects: A Plethora of Systematic Biases, August 2010

3145 Sabrina Di Addario and Daniela Vuri, Entrepreneurship and Market Size. The Case of Young College Graduates in Italy, August 2010

3146 Shoshana Amyra Grossbard and Alfredo Marvăo Pereira, Will Women Save more than Men? A Theoretical Model of Savings and Marriage, August 2010

3147 Jarko Fidrmuc, Time-Varying Exchange Rate Basket in China from 2005 to 2009, August 2010

3148 Ilja Neustadt and Peter Zweifel, Is the Welfare State Sustainable? Experimental Evidence on Citizens' Preferences for Redistribution, August 2010

3149 Marcus Dittrich and Andreas Knabe, Wage and Employment Effects of Non-Binding Minimum Wages, August 2010

3150 Shutao Cao, Enchuan Shao and Pedro Silos, Fixed-Term and Permanent Employment Contracts: Theory and Evidence, August 2010

3151 Ludger Woessmann, Cross-Country Evidence on Teacher Performance Pay, August 2010 
3152 Lorenzo C. G. Pozzi, Casper G. de Vries and Jorn Zenhorst, World Equity Premium Based Risk Aversion Estimates, August 2010

3153 Volker Grossmann, Thomas M. Steger and Timo Trimborn, Dynamically Optimal R\&D Subsidization, August 2010

3154 Alexander Haupt, Tim Krieger and Thomas Lange, A Note on Brain Gain and Brain Drain: Permanent Migration and Education Policy, August 2010

3155 António Afonso and Christophe Rault, Long-run Determinants of Sovereign Yields, August 2010

3156 Franziska Tausch, Jan Potters and Arno Riedl, Preferences for Redistribution and Pensions. What can we Learn from Experiments?, August 2010

3157 Martin Kolmar and Andreas Wagener, Inefficient Group Organization as Optimal Adaption to Dominant Environments, August 2010

3158 Kai Carstensen, Klaus Wohlrabe and Christina Ziegler, Predictive Ability of Business Cycle Indicators under Test: A Case Study for the Euro Area Industrial Production, August 2010

3159 Horst Rottmann and Timo Wollmershäuser, A Micro Data Approach to the Identification of Credit Crunches, August 2010

3160 Philip E. Graves, Appropriate Fiscal Policy over the Business Cycle: Proper Stimulus Policies Can Work, August 2010

3161 Michael Binder and Marcel Bluhm, On the Conditional Effects of IMF Program Participation on Output Growth, August 2010

3162 Michael Binder, Qianying Chen, and Xuan Zhang, On the Effects of Monetary Policy Shocks on Exchange Rates, August 2010

3163 Felix J. Bierbrauer, On the Optimality of Optimal Income Taxation, August 2010

3164 Nikolaus Wolf, Europe's Great Depression - Coordination Failure after the First World War, September 2010

3165 Dan Kovenock and Brian Roberson, Conflicts with Multiple Battlefields, September 2010 